\title{
A Family of Variable Step-Size Affine Projection Adaptive Filtering Algorithms
}

\author{
Mohammad Shams Esfand Abadi, Vahid Mehrdad, Azizollah Gholipour and Majid Noroozi
}

\begin{abstract}
This paper presents a family variable step-size (VSS) affine projection (AP) adaptive filtering algorithms with good convergence speed and low steady state mean square error features. In the following, the family of VSS selective partial updates (SPU) affine projection algorithms are established which reduce the computational complexity. The stability bounds of the family of APA and SPU-APA algorithms are analyzed based on the energy conservation arguments. This analysis does not need to assume a Gaussian or white distribution for the regressors. We demonstrate the good performance of the proposed algorithms through simulations in system identification and acoustic echo cancellation scenarios.
\end{abstract}

Index Terms - Adaptive filter, affine projection, selective partial update, variable step-size, stability analysis.

\section{INTRODUCTION}

Adaptive filtering has been, and still is, an area of active research that plays an active role in an ever increasing number of applications such as noise cancellation, channel estimation, channel equalization and acoustic echo cancellation [1], [2]. The least mean square (LMS) and its normalized version (NLMS) are the workhorses of adaptive filtering. In the presence of colored input signals, the LMS and NLMS algorithms have extremely slow convergence rates. To solve this problem a number of adaptive filtering structures based on affine subspace projections [3], [4], [5], data reusing adaptive algorithms [6], [7], [8], Block adaptive filters [2] and multirate techniques have been proposed in the literature [9], [10], [11]. In all these algorithms the selected fixed step-size can change the convergence speed and the steady-state mean square error. It is well known that the steady-state mean square error (MSE) is decreases, when the step-size is decreases while the convergence speed increases when the step-size increases. By optimally selecting the step-size, during the adaptation, we can obtain both fast convergence rate and low steady-state mean square error [12], [13], [14], [15].

These selections are based on various criteria. In [12], the squared instantaneous errors were used. To improve noise immunity under Gaussian noise, the squared autocorrelation of errors at adjacent time was used in [14], and in [15], the fourth-order cumulant of instantaneous error was adopted.

Manuscript submitted on Aug 10. 2009.

Mohammad Shams Esfand Abadi (M. S. E. Abadi) is with the Shahid Rajaee University, Department of Electrical Engineering, Tehran, Iran, Email: mshams@srttu.edu. Azizollah Gholipour and Vahid Mehrdad are MSc students in Shahid Rajaee University, Email: vmehrdad@srttu.edu. Majid Noroozi is the BSc student in Shahid Rajaee University, Email: mnroozi@srttu.edu.
Important examples of two new variable step-size (VSS) versions of the NLMS and the APA algorithm (APA) can be found in [16]. In [16], the norm of the projected weighted error vector is used as a criterion to determine how close the adaptive filter is to optimum performance.

Another feature that should be noticed in VSS adaptive filter algorithms is computational complexity. Several adaptive filters with fixed step-size such as the adaptive filter algorithms with selective partial updates have been proposed to reduce the computational complexity. These algorithms update only a subset of the filter coefficients in each time iteration. The Max-NLMS [17], the MMax-NLMS [18], [19], the variants of the selective partial update normalized least mean square algorithms (SPU-NLMS) [20], [21], [22], and SPU affine projection (SPUAP) algorithm [21], are important examples of this family of adaptive filter algorithms.

In this paper we extend the approach in [16] to establish of the family of VSS-APA. Also to reduce the computational complexity, the family of VSS-SPU-APA is established. The mean-square stability of these VSS adaptive algorithms is analyzed based on the energy conservation relations. This analysis does not need to assume a Gaussian or white distribution for the regressors.

What we propose in this paper can be summarized as follows:

- The establishment of the family VSS-AP algorithms.

- The establishment of the family of VSS-SPU-AP algorithms.

- Mean-square stability analysis of the family of AP, and SPU-AP algorithms.

- Demonstrating of the presented algorithms in system identification and acoustic echo cancellation scenarios.

We have organized our paper as follows: In the following the NLMS, and SPU-NLMS algorithms will be briefly reviewed. In the next section, the family of APA is presented. In Section IV, the family of SPU-APA is introduced. Section $\mathrm{V}$ presents the generic variable step-size update equation. The variable step-size adaptive filters are established in Section VI. The computational complexity of the VSS adaptive filters is discussed in Section VII. Finally, before concluding the paper, we demonstrate the usefulness of these algorithms by presenting several experimental results.

Throughout the paper, the following notations are adopted:

$\begin{array}{ll}\|.\| & \text { Euclidean norm of a vector. } \\ \|\|^{2} \quad \text { Squared Euclidean norm of a vector. }\end{array}$


$\|\mathrm{t}\|_{\Sigma}^{2} \quad \Sigma$ Weighted Euclidean norm of a column vector $\mathrm{t}$ defined as $\mathrm{t}^{\mathrm{T}} \sum \mathrm{t}$.

$\operatorname{Tr}($.$) \quad Trace of a matrix.$

(.) ${ }^{\mathrm{T}} \quad$ Transpose of a vector or a matrix.

$\mathrm{A} \otimes \mathrm{B} \quad$ Kronecker product of matrices A and B .

Vect( T ) Creating an $\mathrm{M}^{2} \times 1$ column vector $\mathrm{t}$ through stacking the columns of the $M \times M$ matrix $\mathrm{T}$.

Vect(t) Creating an $M \times M$ matrix $\mathrm{T}$ from the $\mathrm{M}^{2} \times 1$ column vector $\mathrm{t}$.

$\lambda_{\max }$ The largest eigenvalue of a matrix.

$\mathrm{R}^{+} \quad$ The set of positive real numbers.

$\mathrm{E}\{$.$\} \quad Expectation operator.$

\section{BACKGROUND ON NLMS, AND SPU-NLMS ALGORITHMS}

Figure 1 shows a typical adaptive filter setup, where $\mathbf{x}(n)$, $d(n)$ and $e(n)$ are the input, the desired and output error signals, respectively. Here, $\mathbf{h}(\mathrm{n})$ is the $M$ ? column vector of filter coefficients at iteration $\mathrm{n}$. The desired signal assumed to conform to the following linear data model

$$
\mathrm{d}(\mathrm{n})=\mathbf{x}^{\mathrm{T}}(\mathrm{n}) \mathbf{h}_{\mathrm{t}}+\mathrm{v}(\mathrm{n})
$$

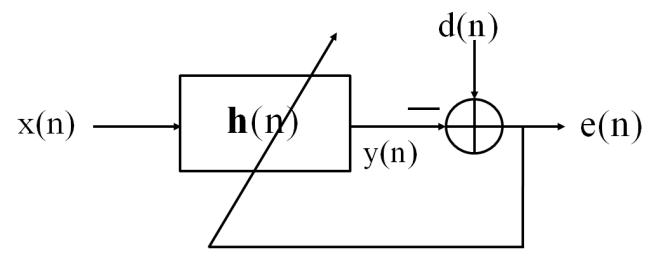

Fig. 1. A typical adaptive filter setup.

It is well known that the NLMS algorithm can be derived from the solution of the following optimization problem:

$$
\min _{\mathbf{h}(\mathrm{n}+1)}\|\mathbf{h}(\mathrm{n}+1)-\mathbf{h}(\mathrm{n})\|^{2}
$$

subject to

$$
\mathrm{d}(\mathrm{n})=\mathbf{x}^{\mathrm{T}}(\mathrm{n}) \mathbf{h}(\mathrm{n}+1)
$$

Using the method of Lagrange multipliers to solve this optimization problem leads to the following recursion

$$
\mathbf{h}(\mathrm{n}+1)=\mathbf{h}(\mathrm{n})+\frac{\mu}{\|\mathbf{x}(\mathrm{n})\|^{2}} \mathbf{x}(\mathrm{n}) \mathrm{e}(\mathrm{n})
$$

Where $e(n)=d(n)-x^{T}(n) h(n)$, and $\mu$ is the step-size that determines the convergence speed and excess MSE (EMSE). Now partition the input signal vector and the vector of filter coefficients into B blocks each of length $\mathrm{L}(\mathrm{B}=\mathrm{M} / \mathrm{L}$ and is an integer $)$ which are defined as

$$
\begin{aligned}
& \mathbf{x}(n)=\left[\mathbf{x}_{1}^{\mathrm{T}}(\mathrm{n}), \mathbf{x}_{2}^{\mathrm{T}}(\mathrm{n}), \ldots, \mathbf{x}_{\mathrm{B}}^{\mathrm{T}}(\mathrm{n})\right]^{\mathrm{T}} \\
& \mathbf{h}(\mathrm{n})=\left[\mathbf{h}_{1}^{\mathrm{T}}(\mathrm{n}), \mathbf{h}_{2}^{\mathrm{T}}(\mathrm{n}), \ldots, \mathbf{h}_{\mathrm{B}}^{\mathrm{T}}(\mathrm{n})\right]^{\mathrm{T}}
\end{aligned}
$$

The SPU-NLMS algorithm for a single block update at every iteration minimizes following optimization problem

$$
\min _{\mathbf{h}_{\mathbf{j}}(\mathrm{n}+1)}\left\|\mathbf{h}_{\mathbf{j}}(\mathrm{n}+1)-\mathbf{h}_{\mathbf{j}}(\mathrm{n})\right\|^{2}
$$

subject to (3), where $\mathrm{j}$ denotes the index of the block that should be updated [21]. Again by using the method of Lagrange multipliers, the update equation for SPU-NLMS is given by

$$
\mathbf{h}_{j}(n)=\mathbf{h}_{j}(n)+\frac{\mu}{\left\|\mathbf{x}_{j}(n)\right\|^{2}} \mathbf{x}_{j}(n) e(n)
$$

Where $j=\operatorname{argmax}\left\|\mathbf{x}_{i}(n)\right\|^{2}$ for $1 \leq \mathrm{i} \leq \mathrm{B}$.

\section{FAMily of AfFine Projection Algorithms (APA)}

Now define the $M \times M$ matrix of the input signal as

$$
\mathbf{X}(\mathrm{n})=[\mathbf{x}(\mathrm{n}), \mathbf{x}(\mathrm{n}-\mathrm{D}), \ldots, \mathbf{x}(\mathrm{n}-(\mathrm{K}-1) \mathrm{D})]
$$

and the $K \times 1$ vector of desired signal as

$$
\mathbf{d}(n)=[d(n), d(n-D), \ldots, d(n-(K-1) D)]^{T}
$$

where $\mathrm{K}$ is positive integer (usually, but not necessarily $\mathrm{K} \leq \mathrm{M})$, and $\mathrm{D}$ is the positive integer parameter $(\mathrm{D} \geq 1)$. that can increase the separation and consequently reduce the correlation among the regressors in $\mathbf{X}(\mathrm{n})$.

The family of APA can be established by minimizing (2) but subject to $\mathbf{d}(\mathrm{n})=\mathbf{X}^{\mathrm{T}}(\mathrm{n}) \mathbf{h}(\mathrm{n})$. Again by using the method of Lagrange multipliers, the filter vector update equation for the family of APA is given by

$$
\mathbf{h}(\mathrm{n}+1)=\mathbf{h}(\mathrm{n})+\mu \mathbf{X}(\mathrm{n}) \mathbf{W}(\mathrm{n}) \mathrm{e}(\mathrm{n})
$$

Where $e(n)$ is the output error vector which is defined as

$$
\mathbf{e}(\mathrm{n})=\mathbf{d}(\mathrm{n})-\mathbf{X}^{\mathrm{T}}(\mathrm{n}) \mathbf{h}(\mathrm{n})
$$

and the matrix $\mathbf{W}(\mathrm{n})$ is obtained from table I. In Table I, $\varepsilon$ is the regularization parameter, and $\mathrm{I}$ is the identity matrix. The NLMS, $\varepsilon$ - NLMS, standard version of the APA, the binormalized datareusing LMS (BNDR-LMS) [16], the regularized APA (RAPA) [15], the NLMS with orthogonal correction factors (NLMS-OCF) [18] are established form (11). From (11), the partial rank algorithm (PRA) [17] can also be established when the adaptation of the filter coefficients is performed only once every $\mathrm{K}$ iteration. 


\section{The Family of Selective Partial Update APA} (SPU-APA).

The SPU-APA solves the following optimization problem

$$
\min _{\mathbf{h}_{\mathrm{F}}(\mathrm{n}+1)}\left\|\mathbf{h}_{\mathrm{F}}(\mathrm{n}+1)-\mathbf{h}_{\mathrm{F}}(\mathrm{n})\right\|^{2}
$$

subject to $\mathbf{d}(\mathrm{n})=\mathbf{X}^{\mathrm{T}}(\mathrm{n}) \mathbf{h}(\mathrm{n})$, where $\mathrm{F}=\left\{\mathrm{j}_{1}, \mathrm{j}_{2}, \ldots, \mathrm{j}_{\mathrm{S}}\right\}$ denote the indices of the $\mathrm{S}$ blocks out of $\mathrm{B}$ blocks that should be updated at every adaptation. Again by using the Lagrange multipliers approach, the filter vector update equation is given by

$$
\mathbf{h}_{\mathrm{F}}(\mathrm{n}+1)=\mathbf{h}_{\mathrm{F}}(\mathrm{n})+\mu \mathbf{X}_{\mathrm{F}}(\mathrm{n})\left(\mathbf{X}_{\mathrm{F}}^{\mathrm{T}}(\mathrm{n}) \mathbf{X}_{\mathrm{F}}(\mathrm{n})\right)^{-1} \mathbf{e}(\mathrm{n})
$$

Where

$$
\mathbf{X}_{\mathrm{F}}(\mathrm{n})=\left[\mathbf{X}_{\mathrm{j}_{1}}^{\mathrm{T}}(\mathrm{n}), \mathbf{X}_{\mathrm{j}_{2}}^{\mathrm{T}}(\mathrm{n}), \ldots, \mathbf{X}_{\mathrm{j}_{\mathrm{S}}}^{\mathrm{T}}(\mathrm{n})\right]^{\mathrm{T}}
$$

is the $S L \times K$ matrix and

$$
\mathbf{X}_{i}(n)=\left[\mathbf{x}_{i}(n), \mathbf{x}_{i}(n-D), \ldots, \mathbf{x}_{i}(n-(K-1) D)\right]^{T}
$$

is the $L \times K$ matrix. The indices of $\mathrm{F}$ are obtained by the following procedure:

1) Compute the following values for $1 \leq \mathrm{i} \leq \mathrm{B}$.

$$
\operatorname{Tr}\left(\mathbf{X}_{\mathrm{i}}^{\mathrm{T}}(\mathrm{n}) \mathbf{X}_{\mathrm{i}}(\mathrm{n})\right)
$$

2) The indices of $F$ are correspond to $S$ largest values of (17).

By setting D = 1, the SPU-APA in [8] can be derived from (14). Furthermore, from (14), the new SPU adaptive algorithms such as SPU-BNDR-LMS, SPU-NLMS-OCF will be established. Also, the SPU-PRA can be established when the adaptation of the filter coefficients is performed only once every $\mathrm{K}$ iterations Equation (14) can be represented in the form of full update equation as

$$
\begin{aligned}
& \mathbf{h}(\mathrm{n}+1)=\mathbf{h}(\mathrm{n})+\mu \mathbf{A}(\mathrm{n}) \mathbf{X}(\mathrm{n}) \\
& \left(\mathbf{X}^{\mathrm{T}}(\mathrm{n}) \mathbf{A}(\mathrm{n}) \mathbf{X}(\mathrm{n})\right)^{-1} \mathbf{e}(\mathrm{n})
\end{aligned}
$$

where the $\mathbf{A}(\mathrm{n})$ matrix is the $M \times M$ diagonal matrix with the 1 and 0 blocks each of length $L$ on the diagonal and the positions of 1's on the diagonal determine which coefficients should be updated in each iteration. The positions of 1 blocks ( $\mathrm{S}$ blocks and $\mathrm{S} \leq \mathrm{B}$ ) on the diagonal of $\mathbf{A}(\mathrm{n})$ matrix for each iteration in the family of SPU-APA are determined by the indices of $\mathrm{F}$.

TABLE I. FAMILY OF AFFINE PROJECTION ADAPTIVE FILTER ALGORITHM
\begin{tabular}{|c|c|c|c|}
\hline Algorithm & $\mathrm{K}$ & $\mathrm{D}$ & $\mathbf{W}(\mathrm{n})$ \\
\hline NLMS & $\mathrm{K}=1$ & $\mathrm{D}=1$ & $\frac{1}{\|\mathbf{x}(\mathrm{n})\|^{2}}$ \\
\hline$\varepsilon$ - NLMS & $\mathrm{K}=1$ & $\mathrm{D}=1$ & $\frac{1}{\varepsilon+\|\mathbf{x}(\mathrm{n})\|^{2}}$ \\
\hline APA & $\mathrm{K} \leq \mathrm{M}$ & $\mathrm{D}=1$ & $\left(\mathbf{X}^{\mathrm{T}}(\mathrm{n}) \mathbf{X}(\mathrm{n})\right)^{-1}$ \\
\hline BNDR-LMS & $\mathrm{K}=2$ & $\mathrm{D}=1$ & $\left(\mathbf{X}^{\mathrm{T}}(\mathrm{n}) \mathbf{X}(\mathrm{n})\right)^{-1}$ \\
\hline R-APA & $\mathrm{K} \leq \mathrm{M}$ & $\mathrm{D}=1$ & $\left(\varepsilon \mathrm{I}+\left(\mathbf{X}^{\mathrm{T}}(\mathrm{n}) \mathbf{X}(\mathrm{n})\right)^{-1}\right.$ \\
\hline NLMS-OCF & $\mathrm{K} \leq \mathrm{M}$ & $\mathrm{D} \geq 1$ & $\left(\mathbf{X}^{\mathrm{T}}(\mathrm{n}) \mathbf{X}(\mathrm{n})\right)^{-1}$ \\
\hline
\end{tabular}

\section{THE GENERIC VARIABLE STEP-SIZE UPdATE EQUATION}

We now proceed by determining the optimum step-size, $\mu^{\mathrm{o}}(\mathrm{n})$ instead of using $\mu$ in the VSS version of (11).

This equation can be stated in terms of weight error vector,

$$
\begin{aligned}
\tilde{\mathbf{h}}(\mathrm{n})= & \mathbf{h}_{\mathrm{t}}-\mathbf{h}(\mathrm{n}) \text {, as } \\
& \sim \\
& \sim \\
\mathbf{h}(\mathrm{n}+1)= & \mathbf{h}(\mathrm{n})+\mu \mathbf{X}(\mathrm{n}) \mathbf{W}(\mathrm{n}) \mathrm{e}(\mathrm{n})
\end{aligned}
$$

Taking the squared Euclidean norm and expectations from both sides of (19),

$$
\begin{aligned}
& \mathrm{E}\left\{\|\tilde{\mathbf{h}}(\mathrm{n}+1)\|^{2}\right\}=\mathrm{E}\left\{\|\tilde{\mathbf{h}}(\mathrm{n})\|^{2}\right\}+\mu^{2} \mathrm{E}\left\{\mathbf{e}^{\mathrm{T}}(\mathrm{n})\right. \\
& \left.\mathbf{B}^{\mathrm{T}}(\mathrm{n}) \mathbf{B}(\mathrm{n}) \mathbf{e}(\mathrm{n})\right\}-2 \mu \mathrm{E}\left\{\mathbf{e}^{\mathrm{T}}(\mathrm{n}) \mathbf{B}^{\mathrm{T}}(\mathrm{n}) \tilde{\mathbf{h}}(\mathrm{n})\right\}
\end{aligned}
$$

where $\mathbf{B}(\mathrm{n})=\mathbf{X}(\mathrm{n}) \mathbf{W}(\mathrm{n})$. Equation (20) can be represented in the form of (21)

$$
\mathrm{E}\left\{\|\tilde{\mathbf{h}}(\mathrm{n}+1)\|^{2}\right\}=\mathrm{E}\left\{\|\tilde{\mathbf{h}}(\mathrm{n})\|^{2}\right\}-\Delta \mu
$$

Where $\Delta \mu$ is given by

$$
\begin{aligned}
& \Delta \mu=-\mu^{2} \mathrm{E}\left\{\mathbf{e}^{\mathrm{T}}(\mathrm{n}) \mathbf{B}^{\mathrm{T}}(\mathrm{n}) \mathbf{B}(\mathrm{n}) \mathbf{e}(\mathrm{n})\right\} \\
& +2 \mu \mathrm{E}\left\{\mathbf{e}^{\mathrm{T}}(\mathrm{n}) \mathbf{B}^{\mathrm{T}}(\mathrm{n}) \tilde{\mathbf{h}}(\mathrm{n})\right\}
\end{aligned}
$$

If $\Delta \mu$ is maximized, then mean-square deviation (MSD) will undergo the largest decrease from iteration $\mathrm{n}$ to iteration $n+1$. The optimum step-size will be found with derivation of $\Delta \mu$ with respect to $\mu, \mathrm{d} \Delta \mu / \mathrm{d} \mu=0$,

$$
\mu^{\mathrm{o}}(\mathrm{n})=\frac{\mathrm{E}\left\{\mathbf{e}^{\mathrm{T}}(\mathrm{n}) \mathbf{B}^{\mathrm{T}}(\mathrm{n}) \tilde{\mathbf{h}}(\mathrm{n})\right\}}{\mathrm{E}\left\{\mathbf{e}^{\mathrm{T}}(\mathrm{n}) \mathbf{B}^{\mathrm{T}}(\mathrm{n}) \mathbf{B}(\mathrm{n}) \mathbf{e}(\mathrm{n})\right\}}
$$

From (1), the vector of desired signal can be stated as 


$$
\mathbf{d}(\mathrm{n})=\mathbf{X}^{\mathrm{T}}(\mathrm{n}) \mathbf{h}_{\mathrm{t}}+\mathbf{v}(\mathrm{n})
$$

Where $\mathbf{v}(\mathrm{n})=\left[\mathrm{v}(\mathrm{n}), \mathrm{v}(\mathrm{n}-\mathrm{D}), ?, \mathrm{v}(\mathrm{n}-(\mathrm{K}-1) \mathrm{D}]^{\mathrm{T}}\right.$ is measurement noise vector assumed to be zero mean, white, Gaussian, and independent of the input signal matrix $\mathbf{X}(\mathrm{n})$. Since $\mathbf{e}(\mathrm{n})=\mathbf{d}(\mathrm{n})-\mathbf{X}^{\mathrm{T}}(\mathrm{n}) \mathbf{h}(\mathrm{n})$ and using (24), we obtain

$$
\mathbf{e}(\mathrm{n})=\mathbf{X}^{\mathrm{T}}(\mathrm{n}) \tilde{\mathbf{h}}(\mathrm{n})+\mathbf{v}(\mathrm{n})
$$

Using the mentioned assumptions for the noise sequence and neglecting the dependency of $\mathbf{h}(n)$ on the past noises, we establish the following two sub equations from the two parts of (23),

\section{- PART I:}

$$
\begin{aligned}
& \mathrm{E}\left\{\mathbf{e}^{\mathrm{T}}(\mathrm{n}) \mathbf{B}^{\mathrm{T}}(\mathrm{n}) \tilde{\mathbf{h}}(\mathrm{n})\right\}=\mathrm{E}\left\{\left(\tilde{\mathbf{h}^{\mathrm{T}}}(\mathrm{n}) \mathbf{X}(\mathrm{n})+\mathbf{v}^{\mathrm{T}}(\mathrm{n})\right)\right. \\
& \left.\left(\mathbf{B}^{\mathrm{T}}(\mathrm{n}) \tilde{\mathbf{h}}(\mathrm{n})\right)\right\}=\tilde{E}\left\{\left(\tilde{\mathbf{h}}^{\mathrm{T}}(\mathrm{n}) \mathbf{X}(\mathrm{n}) \mathbf{B}^{\mathrm{T}}(\mathrm{n}) \tilde{\mathbf{h}}(\mathrm{n})\right\}\right.
\end{aligned}
$$

$$
\text { - PART II: }
$$

$$
\begin{aligned}
& \mathrm{E}\left\{\mathbf{e}^{\mathrm{T}}(\mathrm{n}) \mathbf{B}^{\mathrm{T}}(\mathrm{n}) \mathbf{B}(\mathrm{n}) \mathbf{e}(\mathrm{n})\right\}=\mathrm{E}\left\{\tilde{\mathbf{h}^{\mathrm{T}}}(\mathrm{n}) \mathbf{X}(\mathrm{n})\right. \\
& \left.\mathbf{B}^{\mathrm{T}}(\mathrm{n}) \mathbf{B}(\mathrm{n}) \mathbf{X}^{\mathrm{T}}(\mathrm{n}) \tilde{\mathbf{h}}(\mathrm{n})\right\}+\mathrm{E}\left\{\mathbf{v}^{\mathrm{T}}(\mathrm{n}) \mathbf{B}^{\mathrm{T}}(\mathrm{n})\right.
\end{aligned}
$$$$
\mathbf{B}(\mathrm{n}) \mathbf{v}(\mathrm{n})\}=\tilde{\mathrm{E}}\left\{\tilde{\mathbf{h}}^{\mathrm{T}}(\mathrm{n}) \mathbf{X}(\mathrm{n}) \mathbf{B}^{\mathrm{T}}(\mathrm{n}) \mathbf{B}(\mathrm{n})\right.
$$$$
\left.\mathbf{X}^{\mathrm{T}}(\mathrm{n}) \tilde{\mathbf{h}}(\mathrm{n})\right\}+\sigma_{\mathrm{v}}^{2} \operatorname{Tr}\left(\mathrm{E}\left\{\mathbf{B}^{\mathrm{T}}(\mathrm{n}) \mathbf{B}(\mathrm{n})\right\}\right)
$$

Finally, with defining $\mathbf{C}(\mathrm{n})=\mathbf{B}(\mathrm{n}) \mathbf{X}^{\mathrm{T}}(\mathrm{n})$, the optimum size in (23) becomes

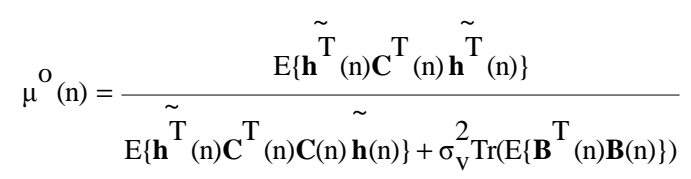

Substituting (28) instead of $\mu$ in (11), the generic variable step-size update equation that covers VSSNLMS, VSSAPA of [16] and the new variable step-size adaptive filters that such as VSS-BNDR-LMS, and VSS-NLMSOCF algorithms will be established. Also, the VSS-PRA will be established when the adaptation of the filter coefficients is performed only once every $\mathrm{K}$ iterations.

\section{Derivation of VARIABle SteP-SizE ADAPTIVE FILTER ALGORITHMS}

We are now in the position to develop the variable step-size adaptive filter algorithms based on generic variable step-size update equation.

\section{A. The Family of Variable Step-Size Affine Projection Algorithms}

From (28), the optimum step-size in the family of affine projection algorithms can be stated as:

$$
\mu^{\mathrm{o}}(\mathrm{n})=\frac{\mathrm{E}\left\{\|\mathbf{q}(\mathrm{n})\|^{2}\right\}}{\mathrm{E}\left\{\|\mathbf{q}(\mathrm{n})\|^{2}\right\}+\sigma_{\mathrm{v}}^{2} \operatorname{Tr}\left(\mathrm{E}\left\{\mathbf{B}^{\mathrm{T}}(\mathrm{n}) \mathbf{B}(\mathrm{n})\right\}\right)}
$$

Where

$$
\mathbf{q}(\mathrm{n})=\mathbf{X}(\mathrm{n}) \mathbf{W}^{\mathrm{T}}(\mathrm{n}) \mathbf{X}^{\mathrm{T}}(\mathrm{n}) \tilde{\mathbf{h}}(\mathrm{n})
$$

Since from (25), $\mathbf{X}^{\mathrm{T}}(\mathrm{n}) \tilde{\mathbf{h}}(\mathrm{n})=\mathbf{e}(\mathrm{n})-\mathbf{v}(\mathrm{n})$, the expectation of $\mathbf{q}(\mathrm{n})$ can be stated as

$$
\mathrm{E}\{\mathbf{q}(\mathrm{n})\}=\mathrm{E}\left\{\mathbf{X}(\mathrm{n}) \mathbf{W}^{\mathrm{T}}(\mathrm{n}) \mathbf{e}(\mathrm{n})\right.
$$

Now, we can estimate $\mathbf{q}(n)$ from the following recursion

$$
\hat{\mathbf{q}}(\mathrm{n})=\hat{\beta} \hat{\mathbf{q}}(\mathrm{n}-1)+(1-\beta) \mathbf{X}(\mathrm{n}) \mathbf{W}^{\mathrm{T}}(\mathrm{n}) \mathbf{e}(\mathrm{n})
$$

Where $\beta(0 \leq \beta<1)$ is the smoothing factor. Using $\|\mathbf{q}(\mathrm{n})\|^{2}$ instead of $\mathrm{E}\left\{\|\hat{\mathbf{q}(\mathrm{n})}\|^{2}\right\}$ in (29), the update equation

for the family of VSS-APA is given by

$$
\mathbf{h}(\mathrm{n}+1)=\mathbf{h}(\mathrm{n})+\mu(\mathrm{n}) \mathbf{X}(\mathrm{n}) \mathbf{W}(\mathrm{n}) \mathbf{e}(\mathrm{n})
$$

Where

$$
\mu(\mathrm{n})=\mu_{\max } \cdot \frac{\|\hat{\mathbf{q}(n)}\|^{2}}{\|\hat{\mathbf{q}(n)}\|^{2}+\Psi}
$$

Where $\Psi=\sigma_{\mathrm{V}}^{2} \operatorname{Tr}\left(\mathrm{E}\left\{\mathbf{B}^{\mathrm{T}}(\mathrm{n}) \mathbf{B}(\mathrm{n})\right\}\right)$. This quantity can be approximated as $\mathrm{K}=\mathrm{SNR}$ (The details of this approximation is given in Appendix A). The step-size changes with $\|\hat{\mathbf{q}(\mathrm{n})}\|^{2}$, and $\Psi$. Also $\mu_{\max }$ is introduced to guarantee the stability and it should be selected in the stability bound(In Appendix $\mathrm{B}$, the stability bounds of the family of APA have been discussed in details).

\section{B. The Family of Variable Step-Size SPU Affine Projection}

To reduce the computational complexity of the VSS-APA, we extend the approach in previous section to the family of SPU-APA to establish the family of VSS-SPU-APA. Following the same approach in previous subsection, the update equation for the family of VSS-SPU-APA can be stated as(The details of this derivation is given in Appendix C),

$$
\mathbf{h}_{\mathrm{F}}(\mathrm{n}+1)=\mathbf{h}_{\mathrm{F}}(\mathrm{n})+\mu(\mathrm{n}) \mathbf{X}_{\mathrm{F}}(\mathrm{n})\left(\mathbf{X}_{\mathrm{F}}^{\mathrm{T}}(\mathrm{n}) \mathbf{X}_{\mathrm{F}}(\mathrm{n})\right)^{-1} \mathbf{e}(\mathrm{n})
$$


Where $\mu(\mathrm{n})$ is given by

$$
\mu(\mathrm{n})=\mu_{\max } \cdot \frac{\left\|\hat{\mathbf{q}}_{\mathrm{F}}(\mathrm{n})\right\|^{2}}{\left\|\hat{\mathbf{q}}_{\mathrm{F}}(\mathrm{n})\right\|^{2}+\Upsilon}
$$

Where $\Upsilon=\sigma_{\mathrm{V}}^{2} \operatorname{Tr}\left(\mathrm{E}\left\{\mathbf{X}_{\mathrm{F}}^{\mathrm{T}}(\mathrm{n}) \mathbf{X}_{\mathrm{F}}(\mathrm{n})\right\}\right)$, and $\mathbf{q}_{\mathrm{F}}(\mathrm{n})$ can be estimated from the following recursion

$$
\hat{\mathbf{q}}_{\mathrm{F}}(\mathrm{n})=\hat{\beta} \hat{\mathbf{q}}_{\mathrm{F}}(\mathrm{n}-1)+(1-\beta) \mathbf{X}_{\mathrm{F}}(\mathrm{n})\left(\mathbf{X}_{\mathrm{F}}^{\mathrm{T}}(\mathrm{n}) \mathbf{X}_{\mathrm{F}}(\mathrm{n})\right)^{-1} \mathbf{e}(\mathrm{n})
$$

In (36), $\Upsilon$ can be approximated as K/SNR (The details of this approximation is given in Appendix A). The step-size changes with $\left\|\hat{\mathbf{q}}_{\mathrm{F}}(\mathrm{n})\right\|^{2}$, and $\Upsilon$. Again, $\mu_{\max }$ should be selected in the stability bound to guarantee the stability (In Appendix B, the stability bounds of the family of SPU-APA have been discussed in details). From (35), the VSS-SPUPRA will also be established when the adaptation of the filter coefficients is performed only once every $\mathrm{K}$ iterations.

\begin{tabular}{|c|c|}
\hline \begin{tabular}{l}
$\mathbb{a}$ \\
\multirow{1}{1}{} \\
$\approx$ \\
$\approx$ \\
$>$
\end{tabular} & $\begin{array}{l}\mathbf{X}(n)=[\mathbf{x}(n), \mathbf{x}(n-D), \ldots, \mathbf{x}(n-(K-1) D)] \\
\hat{\mathbf{q}}(\mathrm{n})=\hat{\beta} \hat{\mathbf{q}}(\mathrm{n}-1)+(1-\beta) \mathbf{X}(\mathrm{n}) \mathbf{W}^{\mathrm{T}}(\mathrm{n}) \mathbf{e}(\mathrm{n}) \\
\mu(\mathrm{n})=\mu_{\max } \cdot \frac{\|\hat{\mathbf{q}(n)}\|^{\wedge}}{\|\mathbf{q}(\mathrm{n})\|^{2}+\Psi}, \Psi \approx \mathrm{K} / \mathrm{SNR} \\
\mathbf{h}(\mathrm{n}+1)=\mathbf{h}(\mathrm{n})+\mu(\mathrm{n}) \mathbf{X}(\mathrm{n}) \mathbf{W}(\mathrm{n}) \mathbf{e}(\mathrm{n})\end{array}$ \\
\hline 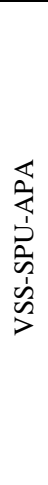 & 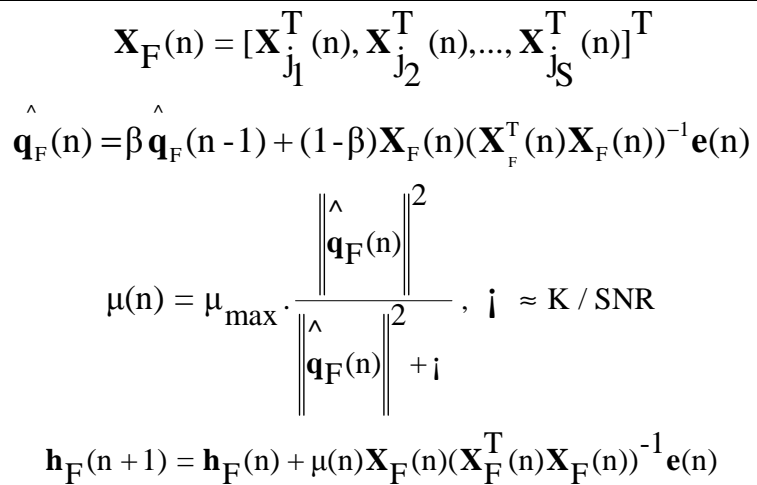 \\
\hline
\end{tabular}
Table II summarizes the presented algorithms.

\section{COMPUTATIONAL COMPLEXITY}

The computational complexity of the VSS adaptive algorithms has been given in Table III. The computational complexity of the APA is from [5]. The SPU-APA needs $\left(\mathrm{K}^{2}+2 \mathrm{~K}\right) \mathrm{SL}+\mathrm{K}^{3}+\mathrm{K}^{2}$ multiplications and 1 division. using the heapsort algorithm [26]. Comparing the update equation for APA and VSS-APA shows that the VSS-APA needs $M$ additional multiplications due to variable stepsize. In VSS-SPU-APA, the additional multiplication is SL. Also this algorithm needs $\operatorname{Blog}_{2} \mathrm{~S}+\mathrm{O}(\mathrm{B})$ comparisons. It is obvious that the computational complexity of VSS-SPUAPA is lower than VSS-APA. Comparing with VSSAPA, the number of reduction in multiplications for VSS-SPUAPA is $(\mathrm{M}-\mathrm{SL})\left(\mathrm{K}^{2}+2 \mathrm{~K}+1\right)$ which is large in some applications such as network and acoustic echo cancellation. Also, the computational complexity of VSS-PRA, and VSSSPU-PRA is reduced by the factor of $K$, because the adaptation of the filter coefficients is performed only once every $\mathrm{K}$ iterations.

\section{Simulation ResUlts}

We justified the performance of the proposed algorithm by carrying out computer simulations in a system identification and a line echo cancellation scenarios.

\section{A. System Identification}

In this experiment, the unknown system has 32 taps and selected at random. The input signal, $x(n)$ is a first order autoregressive $(\mathrm{AR}(1))$ signal generated according to

$$
\mathrm{x}(\mathrm{n})=\rho x(\mathrm{n}-1)+\mathrm{w}(\mathrm{n})
$$

where $w(n)$ is a zero mean white Gaussian signal. The value of $\rho$ is set to 0.9 , generating a highly colored Gaussian signal. The measurement noise, $\mathrm{v}(\mathrm{n})$, with $\sigma_{\mathrm{V}}^{2}=10^{-3}$ was added to the noise free desired signal generated through $\mathrm{d}(\mathrm{n})=\mathbf{h}_{\mathrm{t}}^{\mathrm{T}} \mathbf{x}(\mathrm{n})$ The adaptive filter and the unknown channel are assumed to have the same number of taps. The parameters $\mathrm{K}$ and the number of block (B) are set to 4, and different values for $S$ are used in simulations. In all simulations, the learning curves are obtained by ensemble averaging over 200 independent trials. Also $\mu_{\max }$ is selected in the stability bound to guarantee the stability. Table IV shows the stability bounds of SPU-APA for different values of S. These values are obtained from (67), and (69). Fig. 2 shows the simulated steady-state MSE curves of SPU-AP algorithm as a function of the step-size for colored Gaussian input. The parameter B was set to 4 and different values for $\mathrm{S}$ (2, 3, and 4) were selected. The step-size changes from 0.04 to $\mu_{\max }$ for each parameter adjustment. As we can see, the theoretical values for $\mu_{\max }$ show the good estimation of the stability bound of SPU-AP algorithms. The same as [16], in VSS-APA, $\mu_{\max }$

This algorithm needs $\mathrm{Blog}_{2} \mathrm{~S}+\mathrm{O}(\mathrm{B})$ comparisons when

TABLE III. THE COMPUTATIONAL COMPLEXITY OF THE APA, SPU-APA, VSS-APA, AND VSS-SPU-APA 


\begin{tabular}{|c|c|c|c|c|}
\hline Algorithm & Multiplications & Divisions & $\begin{array}{c}\text { Additional } \\
\text { Multiplications }\end{array}$ & Comparisons \\
\hline APA & $\left(\mathrm{K}^{2}+2 \mathrm{~K}\right) \mathrm{M}+\mathrm{K}^{3}+\mathrm{K}^{2}$ & - & - & - \\
\hline SPU-APA & $\left(\mathrm{K}^{2}+2 \mathrm{~K}\right) \mathrm{SL}+\mathrm{K}^{3}+\mathrm{K}^{2}$ & - & 1 & $\mathrm{Blog}_{2} \mathrm{~S}+\mathrm{O}(\mathrm{B})$ \\
\hline VSS-APA & $\left(\mathrm{K}^{2}+2 \mathrm{~K}\right) \mathrm{M}+\mathrm{K}^{3}+\mathrm{K}^{2}$ & 1 & $\mathrm{M}$ & - \\
\hline VSS-SPU-APA & $\left(\mathrm{K}^{2}+2 \mathrm{~K}\right) \mathrm{SL}+\mathrm{K}^{3}+\mathrm{K}^{2}$ & 1 & $1+\mathrm{SL}$ & $\mathrm{Blog} 2 \mathrm{~S}+\mathrm{O}(\mathrm{B})$ \\
\hline
\end{tabular}

SPU-AP algorithms. The same as [16], in VSS-APA, $\mu_{\max }$ is set to 1 . In VSS-SPU-APA, for $S=2$, and $S=3$, $\mu_{\max }$ is set to 0.3 and 1 respectively. Also, the constant values of $\Psi$ and $\Upsilon$ were set to 0.001 .

Fig. 3 shows the simulated learning curves for APA and VSS-APA algorithms. Different values for $\mu(0.03,0.1,1)$ were used in APA. As we can see, the VSS-APA has fast convergence and low steady-state MSE compared with APA. Fig. 4 shows the results for VSS-SPU-APA. The parameter $S$ was set to 2 , and different values for $\mu(0.03,0.1,0.5)$ was used in SPU-APA. This result shows that the VSS-SPU-APA has fast convergence speed and low steady-state MSE. This fact can be seen in Fig. 5 for $S=3$. Fig. 6 compares the learning curves of VSS-APA, and VSS-SPU-APA. As we can see for $\mathrm{S}=3$, the VSS-SPU-APA will be close to the VSS-APA. Furthermore, the computational complexity of VSS-SPU-APA is lower than VSS-APA. In Fig. 7, we presented the learning curves for PRA and VSS-PRA. Again VSS-PRA has better performance compare with PRA. Fig. 8, and 9 show the results of VSS-SPU-PRA for $S=2$, and $S=3$. The results present better performance for VSS-SPU-PRA compared with SPU-PRA. Fig. 10 compares the VSS-PRA and VSS-SPU-PRA for $S=2$, and $S=3$. For $S=3$, the results will be close to VSS-PRA. Also the computational complexity of VSS-SPU-PRA will be lower than VSS-PRA. In Fig. 11, we presented the learning curves of VSS-APA, VSS-PRA, VSS-SPU-APA, and VSS-SPU-PRA. As we can see, the curve (e) in this figure which is related to VSS-SPU-PRA, has close performance to VSS-APA. In VSS-SPU-PRA, the filter coefficients are partially updated and this adaptation is performed only once every Kiterations. Therefore the reduction of the computational complexity is large in this algorithm.

We have also studied the performance of the presented algorithms for real impulse response system. Fig. 12 shows the impulse response of the car echo path with 256 taps(The impulse response of the car echo path is from [21]). The parameters $\mathrm{K}$, and $\mathrm{B}$ were set to 4 , and the input signal is the same as previous simulations. Fig. 13 compares the performance of the VSS-APA, VSS-SPUAPA, VSS-PRA, and VSS-SPU-PRA. This figure shows that for $S=3$, the convergence speed of VSS-SPU-APA will be close to the VSS-APA.

\section{B. Line Echo Cancellation}

In communications over phone lines, a signal traveling from a far-end point to a near-end point is usually reflected in the form of an echo at the near-end due to mismatches in circuity. The purpose of a line echo canceller (LEC) is to eliminate the echo from received signal. In this experiment the input signal is a speech signal. Also, Fig. 14 shows the impulse response sequence of a typical echo path(The impulse response of the line echo path and the input speech signal is from [5], page 347). In this simulation, the length of adaptive filter is 128. Fig. 15 (a) shows the Far-end signal samples. This signal is a synthetic signal that emulates the properties of speech [5]. Fig. 15 (b) shows the Echo signal. Figs. 16 (a), (b) and (c) show the error signals that are obtained by VSS-SPU-APA with $\mathrm{S}=2$, and $\mathrm{S}=3$, and VSS-APA. As we can see, by increasing the parameter $\mathrm{S}$, the error has smaller amplitude.

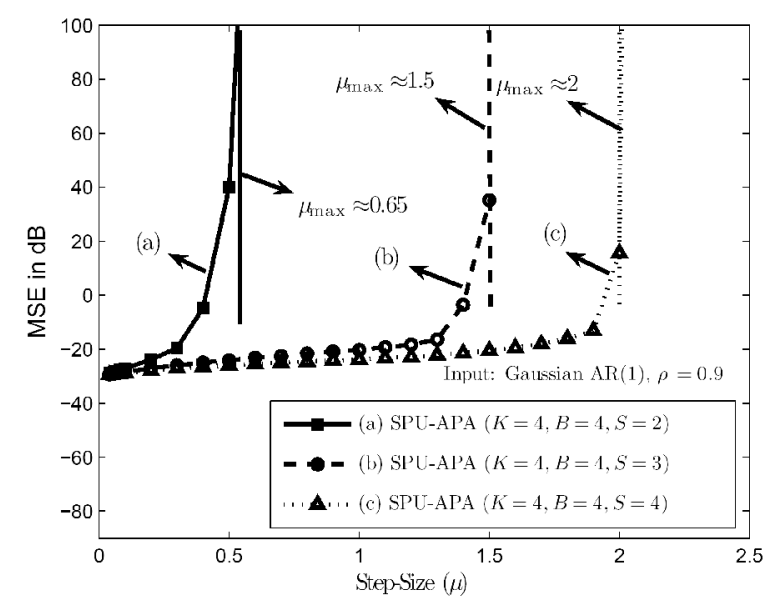

Fig. 2. Simulated steady-state MSE of SPU-APA with $K=4, B=4$ and $S=2$, 3,4 as a function of the step-size for colored Gaussian input signal. 


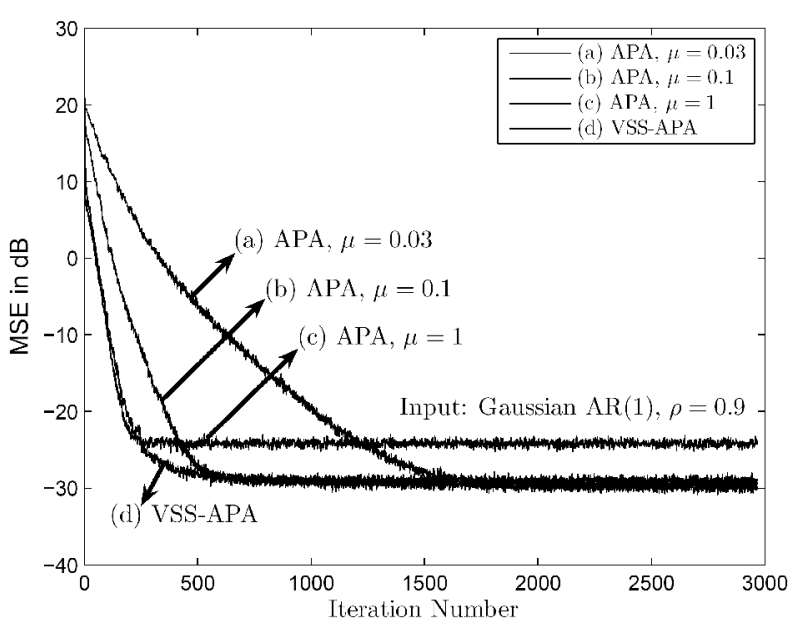

Fig. 3. Learning curves of APA, and VSS-APA for $\mathrm{K}=4$.

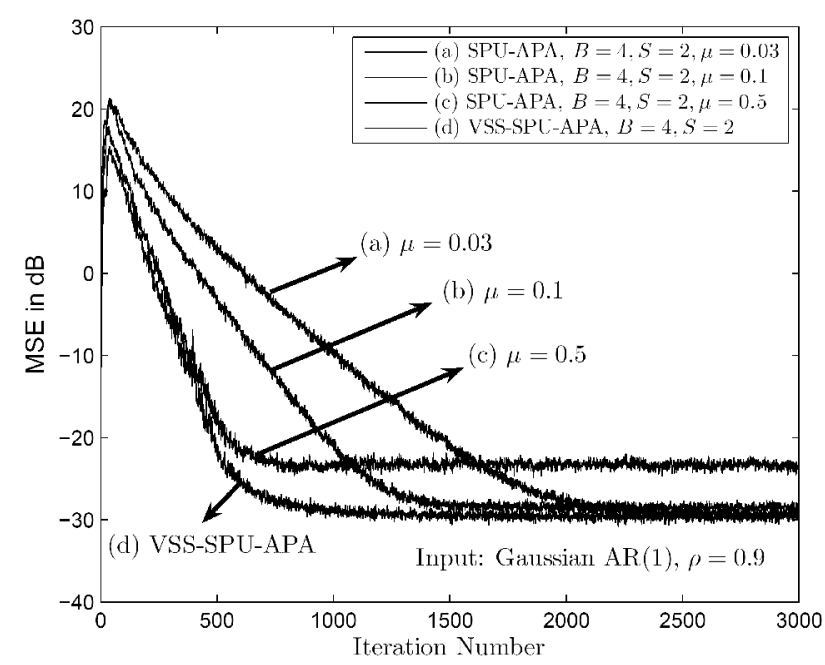

Fig. 4. Learning curves of SPU-APA and VSS-SPU-APA for $\quad K=4, B=$ 4 , and $\mathrm{S}=2$.

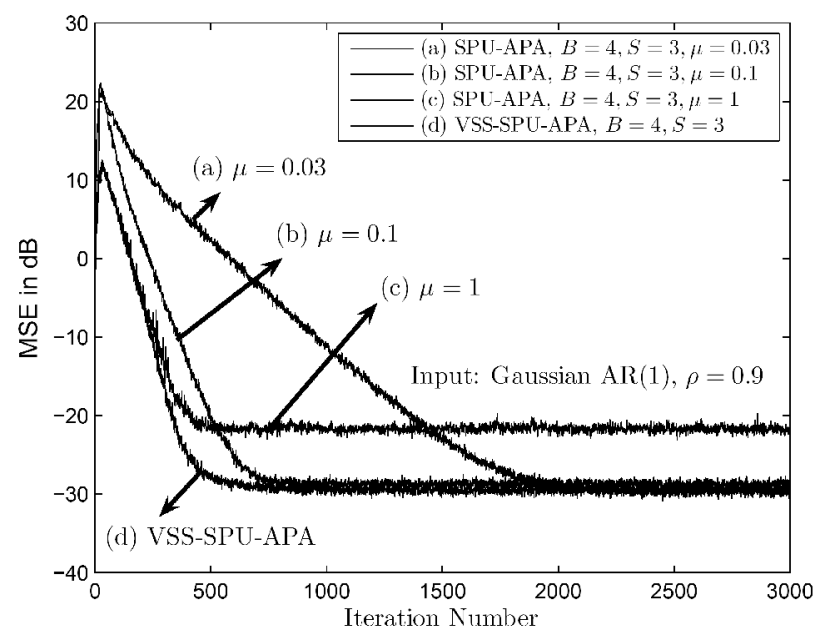

Fig. 5. Learning curves of SPU-APA and VSS-SPU-APA for $K=4, B=$ 4 , and $\mathrm{S}=3$.

\section{CONCLUSIONS}

In this paper we presented the family of VSS-APA and VSS-SPU-APA. These algorithms exhibit fast convergence while reducing steady-state mean square error as compared to the ordinary APA and SPU-APA adaptive filter algorithms. Also in VSS-SPU-APA, the computational complexity was decreased due to partially update of filter coefficients. The stability bounds of these algorithms were analyzed based on the energy conservation arguments. We demonstrated the performance of the presented VSS adaptive algorithms in system identification and acoustic echo cancellation scenarios.

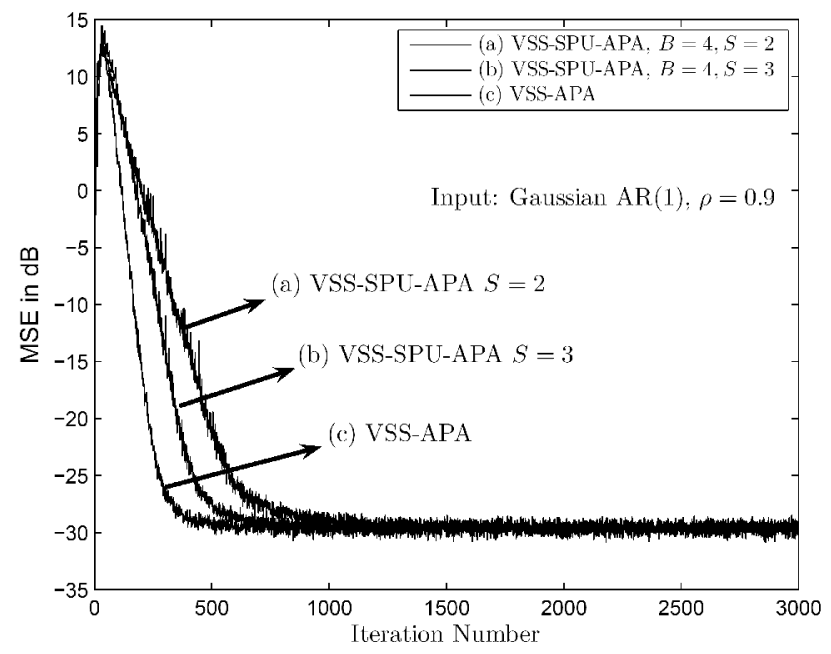

Fig. 6. Comparing the learning curves of VSS-APA, VSS-SPU-APA with S $=2$, and VSS-SPU-APA with $\mathrm{S}=3$.

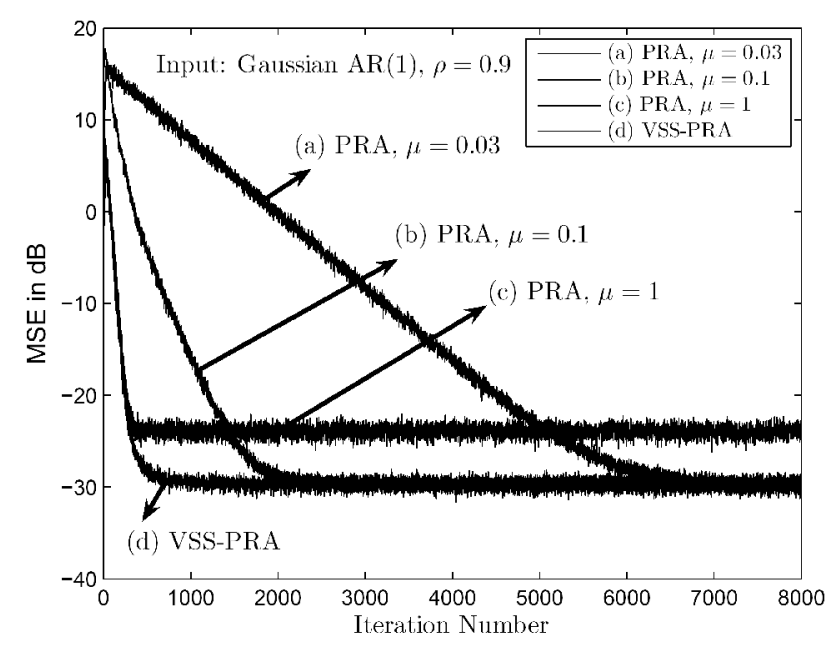

Fig. 7. Learning curves of PRA, and VSS-PRA for $K=4$.

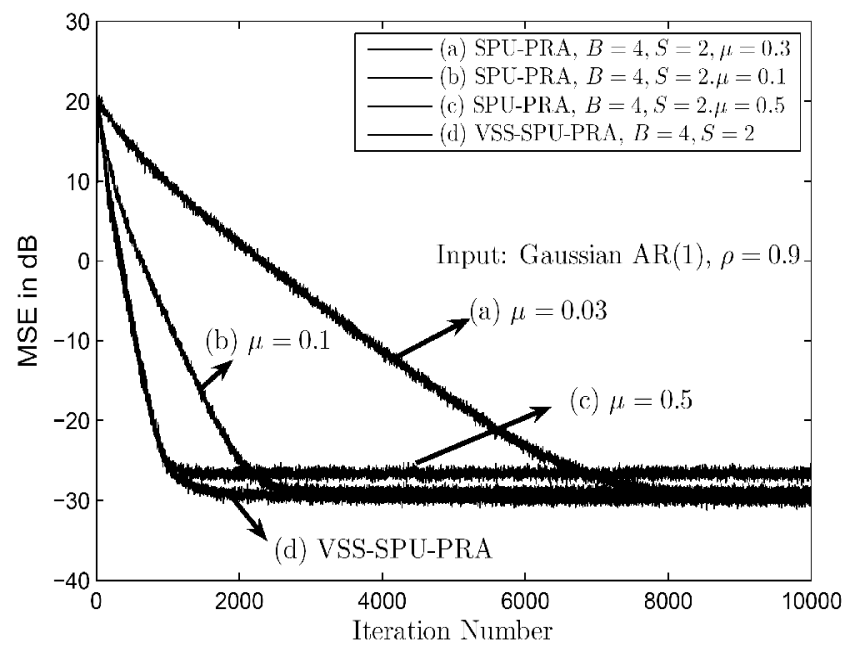

Fig. 8. Learning curves of SPU-PRA and VSS-SPU-PRA for $\quad K=4, B$ $=4$, and $\mathrm{S}=2$. 
TABLE IV. STABILITY BOUNDS OF THE SPU-APA ALGORITHMS WITH DIFFERENT PARAMETERS FOR COLORED GAUSSIANT INPUT.

\begin{tabular}{|c|c|c|c|c|}
\hline & 2 & 1 & 1 & \\
\hline Algorithm & $\lambda_{\max }\left(\mathrm{E}\left\{\mathrm{D}^{\mathrm{T}}(\mathrm{n}) \mathrm{X}^{\mathrm{T}}(\mathrm{n})\right\}\right)$ & $\lambda_{\max }\left(\mathrm{M}^{-1} \mathrm{~N}\right)$ & $\overline{\lambda_{\max }\left(\mathrm{M}^{-1} \mathrm{~N}\right)}$ & $\mu_{\max }$ \\
\hline SPU-APA $(K=4, B=4, S=1)$ & 4.3020 & 0.0315 & 0.5623 & 0.0315 \\
\hline SPU-APA $(K=4, B=4, S=2)$ & 3.6542 & 0.6431 & 2.7474 & 0.6431 \\
\hline SPU-APA $(K=4, B=4, S=3)$ & 3.4910 & 1.4723 & 3.2691 & 1.4723 \\
\hline SPU-APA $(K=4, B=4, S=4)$ & 3.2658 & 2.0002 & 3.4391 & 2.0002 \\
\hline
\end{tabular}

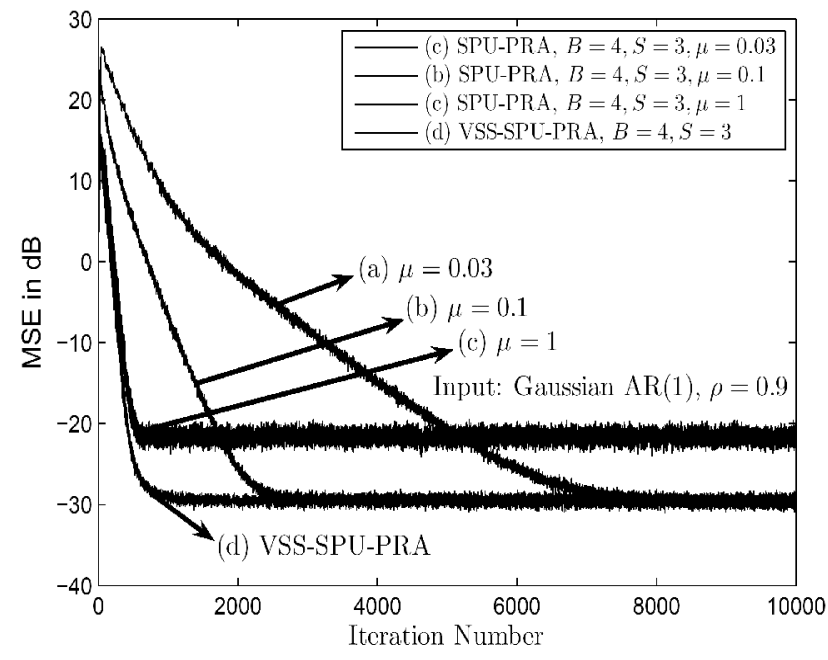

Fig. 9. Learning curves of SPU-PRA and VSS-SPU-PRA for $K=4, B=$ 4 , and $\mathrm{S}=3$.

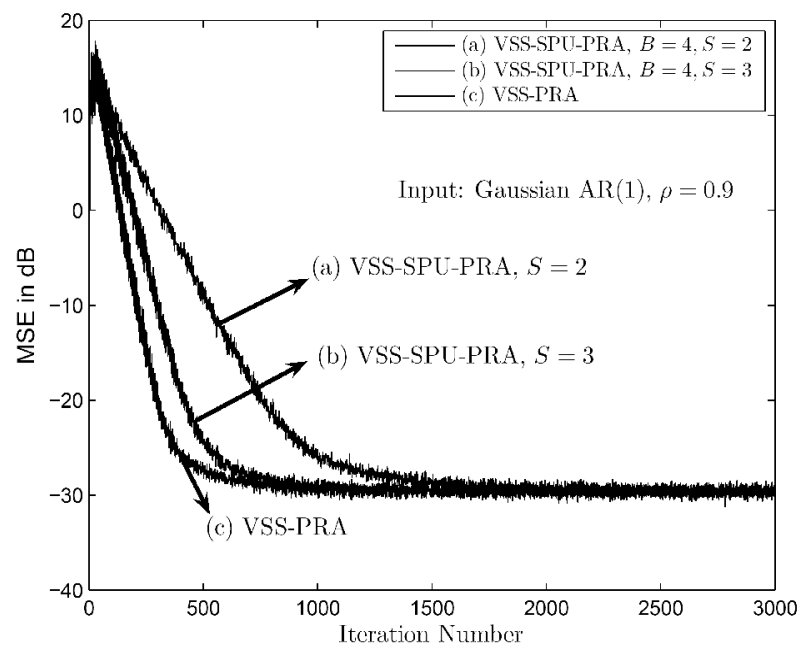

Fig. 10. Comparing the learning curves of VSS-PRA, VSS-SPU-PRA with $\mathrm{S}=2$, and VSS-SPU-PRA with $\mathrm{S}=3$.

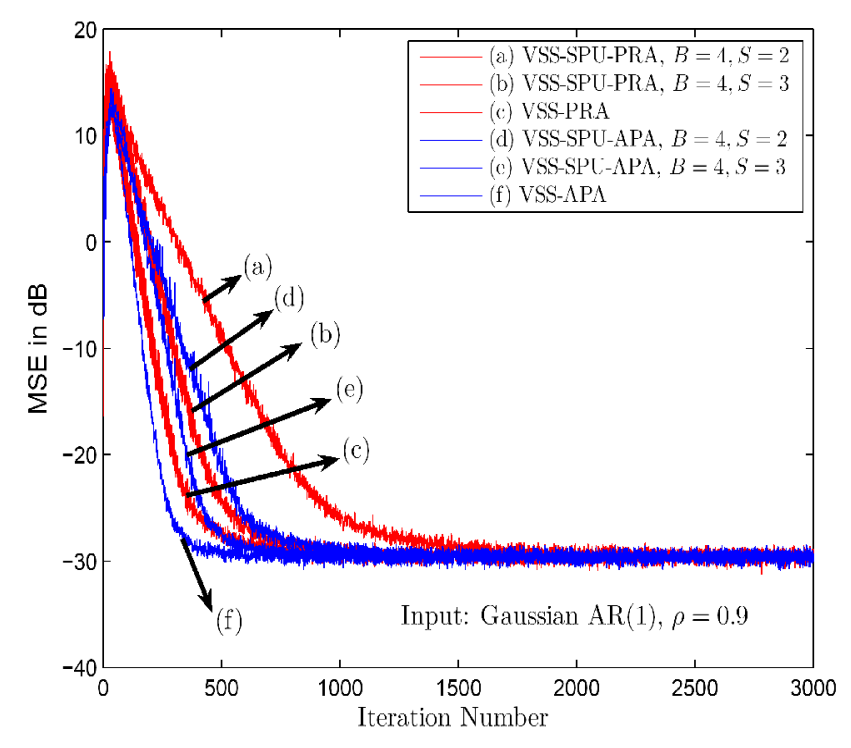

Fig. 11. Comparing the learning curves of VSS-APA, VSS-PRA,

VSS-SPU-APA with $S=2,3$, and VSS-SPU-PRA with $S=2,3$.

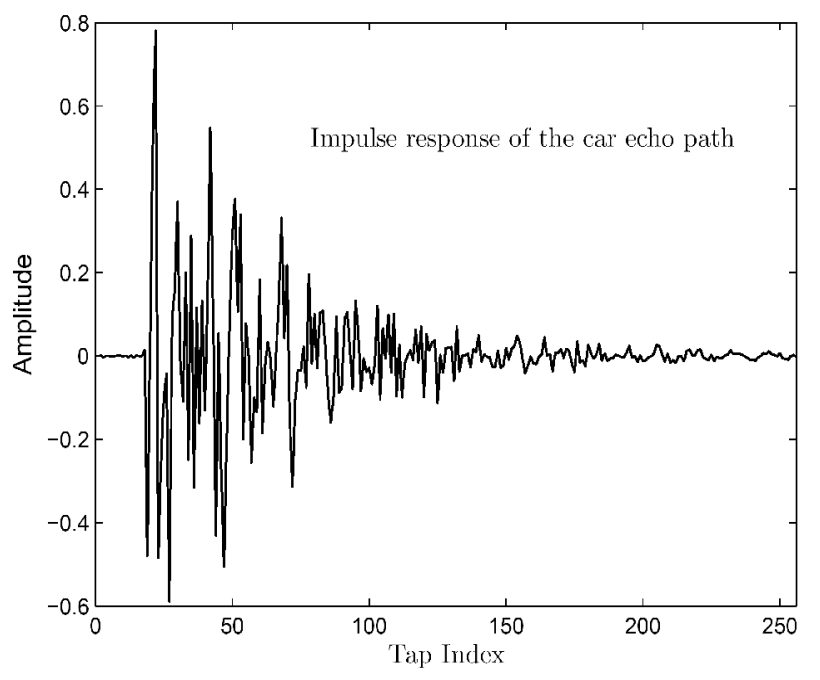

Fig. 12. Impulse response of the car echo path. 


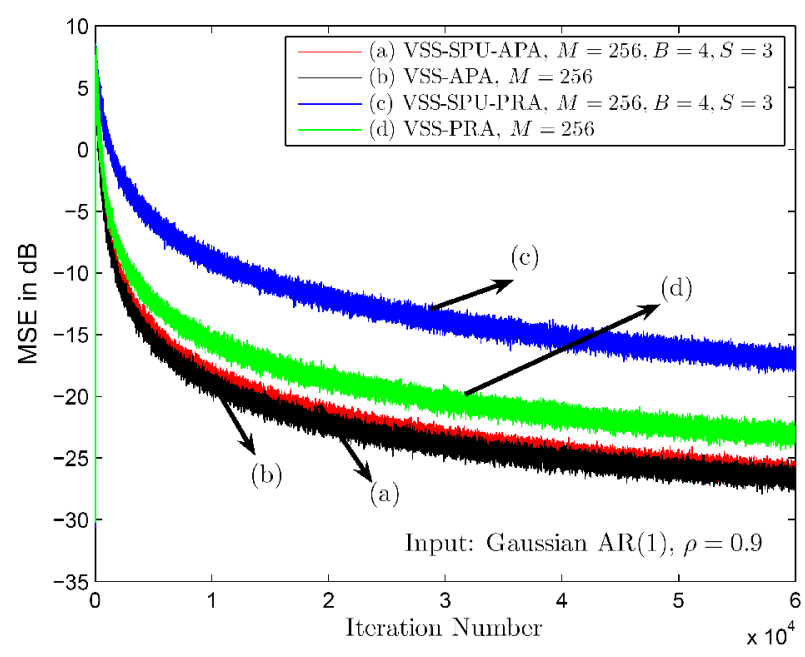

Fig. 13. Comparing the learning curves of VSS-APA, VSS-PRA, VSS-SPU-APA with $S=3$, and VSS-SPU-PRA with $S=3$ when the impulse response of the car echo path should be identified.

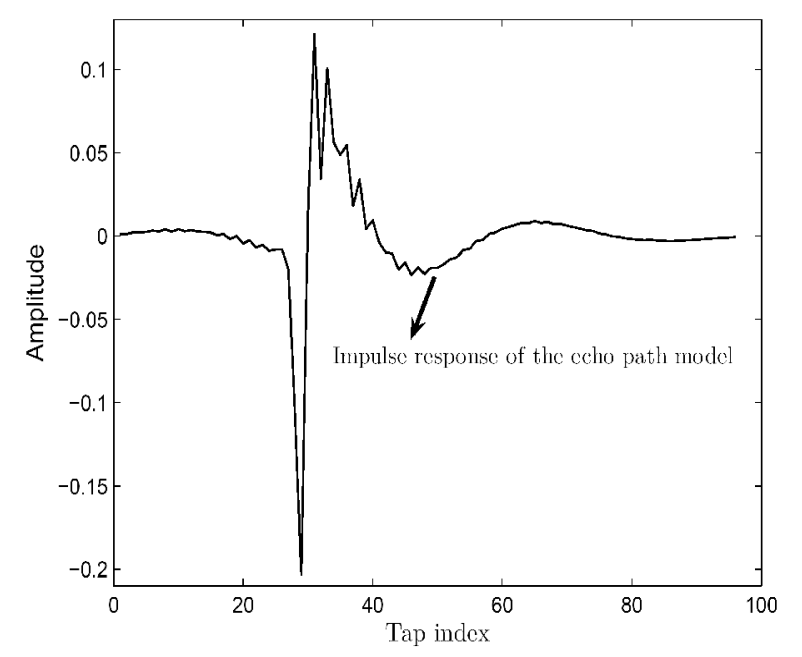

Fig. 14. Impulse response of the line echo path.
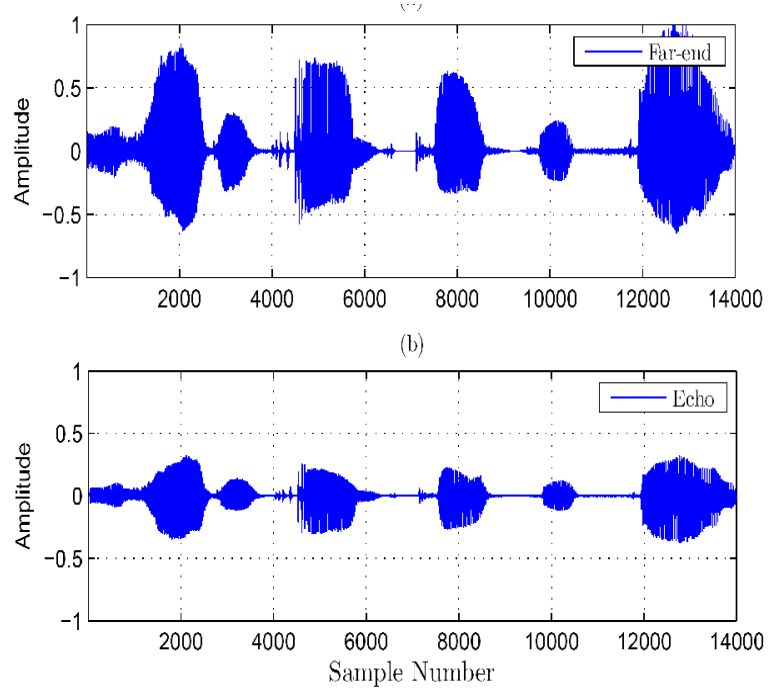

Fig. 15. (a) Far-end signal (b) Echo signal
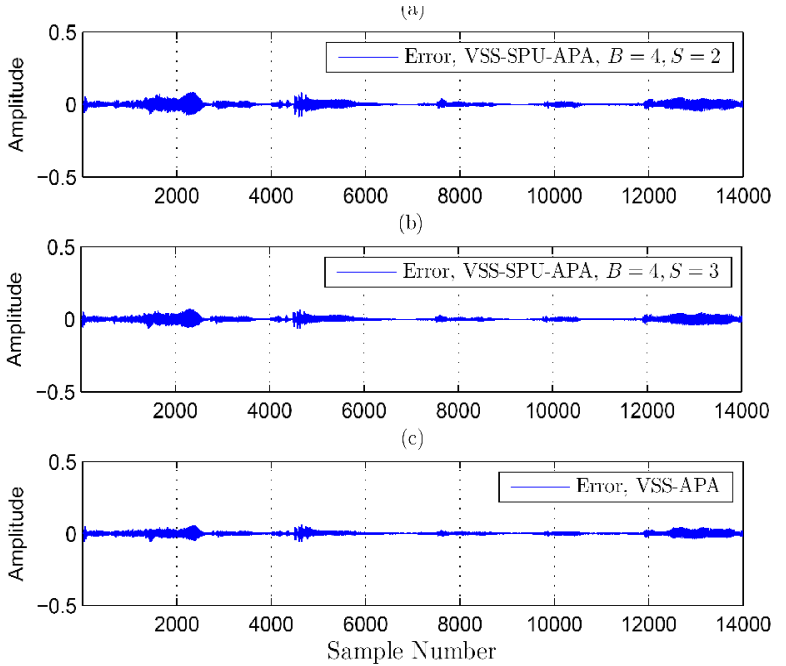

Fig. 16. (a) Error obtained by VSS-SPU-APA with $S=2$ (b) Error obtained by VSS-SPU-APA with $\mathrm{S}=3$ (c) Error obtained by VSS-APA

\section{APPENDIX A}

FINDING AN APPROXIMATION FOR $\Psi$ AND $\Upsilon$ In VSS-APA, the positive constant $\Psi$ can be represented as $\sigma_{\mathrm{v}}^{2} \operatorname{Tr}\left(\mathrm{E}\left\{\left(\mathbf{X}^{\mathrm{T}}(\mathrm{n}) \mathbf{X}(\mathrm{n})\right)^{-1}\right\}\right)$ This quantity is given

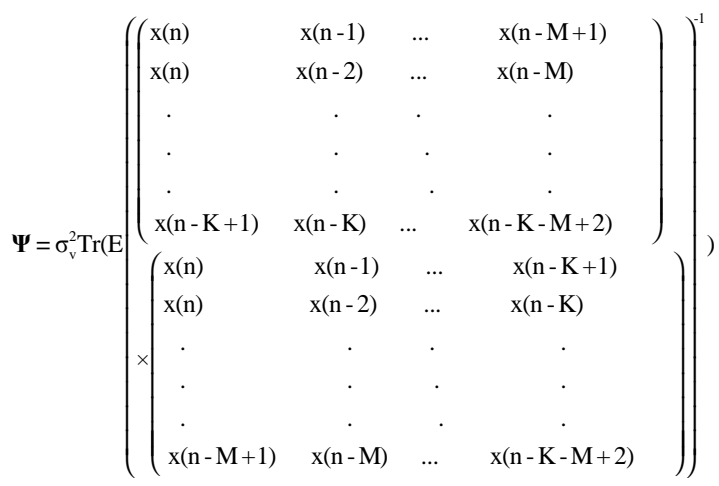

Similar to [27], by neglecting the off-diagonal elements, equation (39) can be obtained by

$$
\Psi=\sigma_{v}^{2} \operatorname{Tr}\left(\mathrm{E}\left(\begin{array}{cccc}
\frac{1}{\|\mathbf{x}(\mathrm{n})\|^{2}} & 0 & \ldots & 0 \\
0 & \frac{1}{\|\mathbf{x}(\mathrm{n}-1)\|^{2}} & \ldots & 0 \\
\cdot & \cdot & \cdot & \cdot \\
\cdot & \cdot & \cdot & \cdot \\
\cdot & \cdot & \cdot & \cdot \\
0 & 0 & \ldots & \frac{1}{\|\mathbf{x}(\mathrm{n}-\mathrm{K}+1)\|^{2}}
\end{array}\right)^{-1}\right.
$$

Now applying the expectation and trace operators, we obtain

$$
\boldsymbol{\Psi}=\sigma_{\mathrm{v}}^{2}\left(\mathrm{E}\left\{\frac{1}{\|\mathbf{x}(\mathrm{n})\|^{2}}\right\}+\mathrm{E}\left\{\frac{1}{\|\mathbf{x}(\mathrm{n})-1\|^{2}}\right\}+\ldots+\mathrm{E}\left\{\frac{1}{\|\mathbf{x}(\mathrm{n}-\mathrm{K}+1)\|^{2}}\right\}\right)
$$

Equation (41) can be stated as

$$
\boldsymbol{\Psi}=\mathrm{K} \cdot \sigma_{\mathrm{V}}^{2} \mathrm{E}\left\{\frac{1}{\|\mathbf{x}(\mathrm{n})\|^{2}}\right\}
$$

Now from [16], we obtain that $\boldsymbol{\Psi}$ can be approximated as 
$\mathrm{K}=\mathrm{S} / \mathrm{NR}$. Therefore $\boldsymbol{\Psi}$ is inversely proportional to SNR and proportional to $\mathrm{K}$.

In VSS-SPU-APA, the parameter $\Upsilon$ is obtained from the following relation

$$
\Upsilon=\sigma_{v}^{2} \operatorname{Tr}\left(E\left(\begin{array}{lccc}
\mathbf{x}_{\mathrm{j}_{1}}^{\mathrm{T}}(\mathrm{n}) & \mathbf{x}_{\mathrm{j}_{2}}^{\mathrm{T}}(\mathrm{n}) & \ldots & \mathbf{x}_{\mathrm{j}_{\mathrm{s}}}^{\mathrm{T}}(\mathrm{n}) \\
\mathbf{x}_{\mathrm{j}_{1}}^{\mathrm{T}}(\mathrm{n}) & \mathbf{x}_{\mathrm{j}_{2}}^{\mathrm{T}}(\mathrm{n}-1) & \ldots & \mathbf{x}_{\mathrm{j}_{\mathrm{s}}}^{\mathrm{T}}(\mathrm{n}-1) \\
\cdot & \cdot & \cdot & \cdot \\
\cdot & \cdot & \cdot & \cdot \\
\cdot & \cdot & \cdot & \cdot \\
\mathbf{x}_{\mathrm{j}_{1}}^{\mathrm{T}}(\mathrm{n}-\mathrm{K}+1) & \mathbf{x}_{\mathrm{j}_{2}}^{\mathrm{T}}(\mathrm{n}-\mathrm{K}+1) & \ldots & \mathbf{x}_{\mathrm{j}_{\mathrm{s}}}^{\mathrm{T}}(\mathrm{n}-\mathrm{K}+1)
\end{array}\right)\right)^{-1}
$$

which can be represented as

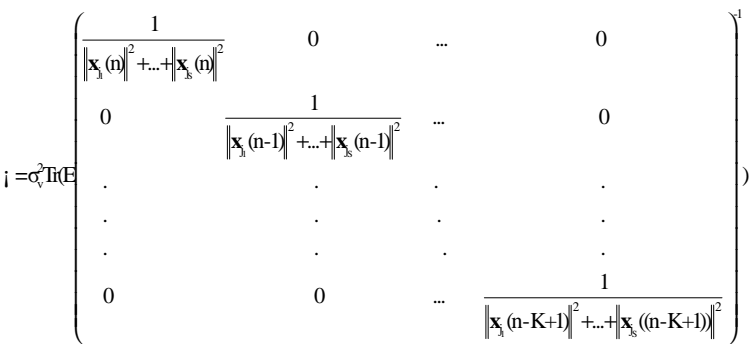

By applying the expectation and trace operators, equation (44) can be stated as

$$
\Upsilon=K \cdot \sigma_{\mathrm{v}}^{2} \mathrm{E}\left\{\frac{1}{\left\|\mathbf{x}_{\mathrm{j}_{1}}(\mathrm{n})\right\|^{2}+\ldots+\left\|\mathbf{x}_{\mathrm{j}_{\mathrm{s}}}(\mathrm{n})\right\|^{2}}\right\}
$$

Now we obtain that $\Upsilon$ can be approximated as $\mathrm{K}=\mathrm{S} / \mathrm{NR}$.

\section{APPENDIX B}

\section{Mean And Mean-Square StabiLity Analysis of The}

FAMILY APA AND SPU-APA

Now we introduce the general filter vector update equation to analysis the mean-square stability of the family of APA, and SPU-APA. The general filter vector update equation is introduced as

$$
\mathbf{h}(\mathrm{n}+1)=\mathbf{h}(\mathrm{n})+\mu \mathbf{C}(\mathrm{n}) \mathbf{X}(\mathrm{n}) \mathbf{Z}(\mathrm{n}) \mathbf{e}(\mathrm{n})
$$

where $\mathbf{C}(n)$, and $\mathbf{Z}(n)$ matrices are obtained from Table $V$. From (46), the family of APA, and SPU-APA can be established(By setting $\mathbf{A}(\mathrm{n})=\mathbf{I}$ in Table $\mathrm{V}$, the family of APA will be established).

The transient behavior of an adaptive filter algorithm is determined by the evolution of the expected squared a priori error in time n, i.e. $\mathrm{E}\left\{\mathrm{e}_{\mathrm{a}}^{2}(\mathrm{n})\right\}$, which is

$$
\mathrm{E}\left\{\mathrm{e}_{\mathrm{a}}^{2}(\mathrm{n})\right\}=\mathrm{E}\left\{\tilde{\mathbf{h}}^{\mathrm{T}}(\mathrm{n}) \mathbf{x}(\mathrm{n}) \mathbf{x}^{\mathrm{T}}(\mathrm{n}) \tilde{\mathbf{h}}(\mathrm{n})\right\}
$$

Where $\tilde{\mathbf{h}}(\mathrm{n})=\mathbf{h}_{\mathrm{t}}-\mathbf{h}(\mathrm{n})$ is the weight-error vector. Employing the common independence assumption [2], we have

$$
\mathrm{E}\left\{\mathrm{e}_{\mathrm{a}}^{2}(\mathrm{n})\right\}=\mathrm{E}\left\{\tilde{\mathbf{h}}^{\mathrm{T}}(\mathrm{n}) \mathbf{R} \tilde{\mathbf{h}}(\mathrm{n})\right\}=\mathrm{E}\left\{\|\tilde{\mathbf{h}}(\mathrm{n})\|_{\mathbf{R}}^{2}\right\}
$$

where the autocorrelation matrix is $\mathbf{R}=\mathrm{E}\left\{\mathbf{x}(\mathrm{n}) \mathbf{x}^{\mathrm{T}}(\mathrm{n})\right\}$.

Thus, to obtain the learning curve, we need to find $\mathrm{E}\left\{\|\tilde{h}(\mathrm{n})\|_{\mathbf{R}}^{2}\right\}$ as a function of $n$. We can recursively obtain $\mathrm{E}\left\{\|\tilde{\mathbf{h}}(\mathrm{n})\|_{\Sigma}^{2}\right\}$, where $\Sigma$ is a positive definite symmetric matrix whose dimension is commensurate with that of $\mathbf{h}(\mathrm{n})$. If we substitute (1) into (12), the relation between output estimation error vector, the a priori error vector and the noise vector is

$$
\mathbf{e}(\mathrm{n})=\mathbf{e}_{\mathrm{a}}(\mathrm{n})+\mathbf{v}(\mathrm{n})
$$

where $\mathbf{e}_{\mathrm{a}}(\mathrm{n})=\mathbf{X}^{\mathrm{T}}(\mathrm{n}) \tilde{\mathbf{h}}(\mathrm{n})$ is the a priori error vector. By substituting (49) in (46), the generic weight error vector update equation can be stated as

$$
\tilde{\mathbf{h}}(\mathrm{n}+1)=\tilde{\mathbf{h}}(\mathrm{n})+\mu \mathrm{C}(\mathrm{n}) \mathbf{X}(\mathrm{n}) \mathbf{Z}(\mathrm{n})\left(\mathbf{X}^{\mathrm{T}}(\mathrm{n}) \tilde{\mathbf{h}}(\mathrm{n})+\mathbf{v}(\mathrm{n})\right)
$$

By defining $\mathbf{D}(\mathrm{n})=\mathbf{Z}^{\mathrm{T}}(\mathrm{n}) \mathbf{X}^{\mathrm{T}}(\mathrm{n}) \mathbf{C}^{\mathrm{T}}(\mathrm{n})$, the $\Sigma$ weighted norm of both sides of (50) is

$$
\|\tilde{\mathbf{h}}(\mathrm{n}+1)\|_{\Sigma}^{2}=\|\tilde{\mathbf{h}}(\mathrm{n})\|_{\Sigma^{\prime}}^{2}+\mu^{2} \mathbf{v}^{\mathrm{T}}(\mathrm{n}) \mathbf{X}^{\Sigma}(\mathrm{n}) \mathbf{v}(\mathrm{n})+
$$

$\{$ Cross terms involving one instance of $\mathbf{v}(n)\}$

Where

$$
\begin{gathered}
\Sigma^{\prime}=\sum-\mu \sum \mathbf{D}^{\mathrm{T}}(\mathrm{n}) \mathbf{X}^{\mathrm{T}}(\mathrm{n})-\mu \mathbf{X}(\mathrm{n}) \mathbf{D}(\mathrm{n})+ \\
\mu^{2} \mathbf{X}(\mathrm{n}) \mathbf{X}^{\Sigma}(\mathrm{n}) \mathbf{X}^{\mathrm{T}}(\mathrm{n}) \\
\mathbf{X}^{\Sigma}(\mathrm{n})=\mathbf{D}(\mathrm{n}) \Sigma \mathbf{D}^{\mathrm{T}}(\mathrm{n})
\end{gathered}
$$

Taking the expectation from both sides of (51) yields

$$
\begin{aligned}
& \mathrm{E}\left\{\|\tilde{\mathbf{h}}(\mathrm{n}+1)\|_{\Sigma}^{2}\right\}=\mathrm{E}\left\{\|\tilde{\mathbf{h}}(\mathrm{n})\|_{\Sigma^{\prime}}^{2}\right\}+ \\
& \mu^{2} \mathrm{E}\left\{\mathbf{v}^{\mathrm{T}}(\mathrm{n}) \mathbf{X}^{\Sigma}(\mathrm{n}) \mathbf{v}(\mathrm{n})\right\}
\end{aligned}
$$

We now obtain the time evolution of the weight-error variance. The expectation of $\|\tilde{\mathbf{h}}(\mathrm{n})\|_{\Sigma^{\prime}}^{2}$ is difficult to calculate 


\begin{tabular}{|c|c|c|c|c|}
\hline Algorithm & $\mathbf{K}$ & $\mathbf{D}$ & $\mathbf{C}(\mathbf{n})$ & $\mathbf{Z}(\mathrm{n})$ \\
\hline SPU- APA & $\mathrm{K} \leq \mathrm{M}$ & $\mathrm{D}=1$ & $\mathbf{A}(\mathrm{n}) \mathbf{I}$ & $\left(\mathbf{X}^{\mathrm{T}}(\mathrm{n}) \mathbf{A}(\mathrm{n}) \mathbf{X}(\mathrm{n})\right)^{-1}$ \\
\hline SPU- BNDR-LMS & $\mathrm{K}=2$ & $\mathrm{D}=1$ & $\mathbf{A}(\mathrm{n}) \mathbf{I}$ & $\left(\mathbf{X}^{\mathrm{T}}(\mathrm{n}) \mathbf{A}(\mathrm{n}) \mathbf{X}(\mathrm{n})\right)^{-1}$ \\
\hline SPU- R-APA & $\mathrm{K} \leq \mathrm{M}$ & $\mathrm{D}=1$ & $\mathbf{A}(\mathrm{n}) \mathbf{I}$ & $\left(\varepsilon \mathbf{I}^{-1} \mathbf{X}^{\mathrm{T}}(\mathrm{n}) \mathbf{A}(\mathrm{n}) \mathbf{X}(\mathrm{n})\right)^{-1}$ \\
\hline SPU- NLMS-OCF & $\mathrm{K} \leq \mathrm{M}$ & $\mathrm{D} \geq 1$ & $\mathbf{A}(\mathrm{n}) \mathbf{I}$ & $\left(\mathbf{X}^{\mathrm{T}}(\mathrm{n}) \mathbf{A}(\mathrm{n}) \mathbf{X}(\mathrm{n})\right)^{-1}$ \\
\hline
\end{tabular}

Because of the dependency of $\Sigma^{\prime}$ on $\mathbf{C}(\mathrm{n}), \mathbf{Z}(\mathrm{n}), \mathbf{X}(\mathrm{n})$, and of $\mathbf{h}(n)$ on prior regressors. To solve this problem, we need to use the following independence assumptions [4]:

1) $\mathbf{X}(n)$ is independent and identically distributed sequence matrix. This assumption guarantees that $\mathbf{h}(\mathrm{n})$ is independent of both $\Sigma^{\prime}$ and $\mathbf{X}(\mathrm{n})$.

2) $\mathbf{h}(n)$ is independent of $\mathbf{D}^{T}(n) \mathbf{X}^{T}(n)$

Using these assumptions, the final results is

$$
\begin{aligned}
& \mathrm{E}\left\{\|\tilde{\mathbf{h}}(\mathrm{n}+1)\|_{\Sigma}^{2}\right\}=\mathrm{E}\left\{\|\tilde{\mathbf{h}}(\mathrm{n})\|_{\Sigma^{\prime}}^{2}\right\}+ \\
& \mu^{2} \mathrm{E}\left\{\mathbf{v}^{\mathrm{T}}(\mathrm{n}) \mathbf{X}^{\Sigma}(\mathrm{n}) \mathbf{v}(\mathrm{n})\right\}
\end{aligned}
$$

Where

$$
\begin{aligned}
& \Sigma^{\prime}=\Sigma-\mu \Sigma E\left\{\mathbf{D}^{\mathrm{T}}(\mathrm{n}) \mathbf{X}^{\mathrm{T}}(\mathrm{n})\right\}- \\
& \mu \mathrm{E}\{\mathbf{X}(\mathrm{n}) \mathbf{D}(\mathrm{n})\} \Sigma+\mu^{2} \mathrm{E}\left\{\mathbf{X}(\mathrm{n}) \mathbf{X}^{\Sigma}(\mathrm{n}) \mathbf{X}^{\mathrm{T}}(\mathrm{n})\right\}
\end{aligned}
$$

Looking only at the second term of the right hand side of (55) we write

$$
\begin{aligned}
& \mathrm{E}\left\{\mathbf{v}^{\mathrm{T}}(\mathrm{n}) \mathbf{X}^{\Sigma}(\mathrm{n}) \mathbf{v}(\mathrm{n})\right\}=\mathrm{E}\left\{\operatorname{Tr}\left(\mathbf{v}(\mathrm{n}) \mathbf{v}^{\mathrm{T}}(\mathrm{n}) \mathbf{X}^{\Sigma}(\mathrm{n})\right)\right\} \\
& =\operatorname{Tr}\left(\mathrm{E}\left\{\mathbf{v}(\mathrm{n}) \mathbf{v}^{\mathrm{T}}(\mathrm{n})\right\} \mathrm{E}\left\{\mathbf{X}^{\Sigma}(\mathrm{n})\right\}\right)
\end{aligned}
$$

Since $\mathrm{E}\left\{\mathbf{v}(\mathrm{n}) \mathbf{v}^{\mathrm{T}}(\mathrm{n})\right\}=\sigma_{\mathbf{V}}^{2} \mathbf{I}$, equation (55) can be stated as

$$
\mathrm{E}\left\{\|\tilde{\mathbf{h}}(\mathrm{n}+1)\|_{\Sigma}^{2}\right\}=\mathrm{E}\left\{\|\tilde{\mathbf{h}}(\mathrm{n})\|_{\Sigma^{\prime}}^{2}\right\}+\mu^{2} \sigma_{\mathrm{v}}^{2} \operatorname{Tr}\left(\mathrm{E}\left\{\mathbf{X}^{\Sigma}(\mathrm{n})\right\}\right)
$$

Applying the vec(.) operator [28] on both sides of (56) yields

$$
\begin{aligned}
& \operatorname{vec}\left(\Sigma^{\prime}\right)=\operatorname{vec}(\Sigma)-\mu \operatorname{vec}\left(\Sigma E\left\{\mathbf{D}^{\mathrm{T}}(\mathrm{n}) \mathbf{X}^{\mathrm{T}}(\mathrm{n})\right\}\right) \\
& -\mu \operatorname{vec}(\mathrm{E}\{\mathbf{X}(\mathrm{n}) \mathbf{D}(\mathrm{n}) \Sigma\})+ \\
& \mu^{2} \operatorname{vec}\left(\operatorname{E}\left\{\mathbf{X}(\mathrm{n}) \mathbf{X}^{\Sigma}(\mathrm{n}) \mathbf{X}^{\mathrm{T}}(\mathrm{n})\right\}\right)
\end{aligned}
$$

Since in general, $\operatorname{vec}(\mathrm{P} \Sigma \mathrm{Q})=\left(\mathrm{Q}^{\mathrm{T}} \otimes \mathrm{P}\right) \operatorname{vec}(\Sigma) \quad[28]$, equation (59) can be written as

$$
\begin{aligned}
& \sigma^{\prime}=\sigma-\mu(E\{\mathbf{X}(n) \mathbf{D}(\mathrm{n})\} \otimes \mathbf{I}) . \sigma- \\
& \mu(\mathbf{I} \otimes \mathrm{E}\{\mathbf{X}(\mathrm{n}) \mathbf{D}(\mathrm{n})\}) . \sigma+ \\
& \mu^{2}(\mathrm{E}\{\mathbf{X}(\mathrm{n}) \mathbf{D}(\mathrm{n}) \otimes(\mathbf{X}(\mathrm{n}) \mathbf{D}(\mathrm{n}))\}) . \sigma
\end{aligned}
$$

where $\sigma^{\prime}=\operatorname{vec}\left(\Sigma^{\prime}\right)$ and $\sigma=\operatorname{vec}\left(\sum\right)$. By defining the $M^{2} \times M^{2}$ matrix $\mathbf{G}$ as

$$
\begin{aligned}
& \mathbf{G}=\mathbf{I}-\mu \mathrm{E}\{\mathbf{X}(\mathrm{n}) \mathbf{D}(\mathrm{n})\} \otimes \mathbf{I}-\mu \mathbf{I} \otimes \mathrm{E}\{\mathbf{X}(\mathrm{n}) \mathbf{D}(\mathrm{n})\} \\
& +\mu^{2} \mathrm{E}\{(\mathbf{X}(\mathrm{n}) \mathbf{D}(\mathrm{n})) \otimes(\mathbf{X}(\mathrm{n}) \mathbf{D}(\mathrm{n}))\}
\end{aligned}
$$

equation (60) becomes

$$
\sigma^{\prime}=\mathbf{G} \sigma
$$

The second term of the right hand side of (44) is

$$
\operatorname{Tr}\left(\mathrm{E}\left\{\mathbf{X}^{\Sigma}(\mathrm{n})\right\}\right)=\operatorname{Tr}\left(\mathrm{E}\left\{\mathbf{D}^{\mathrm{T}}(\mathrm{n}) \mathbf{D}(\mathrm{n})\right\} . \Sigma\right)
$$

Defining $\gamma$ as

$$
\gamma=\operatorname{vec}\left(\mathrm{E}\left\{\mathbf{D}^{\mathrm{T}}(\mathrm{n}) \mathbf{D}(\mathrm{n})\right\}\right)
$$

we have

$$
\operatorname{Tr}\left(\mathrm{E}\left\{\mathbf{X}^{\Sigma}(\mathrm{n})\right\}\right)=\gamma^{\mathrm{T}} \cdot \sigma
$$

From the above, the recursion of (58) is

$$
\mathrm{E}\left\{\|\tilde{\mathbf{h}}(\mathrm{n}+1)\|_{\sigma}^{2}\right\}=\operatorname{E}\left\{\|\tilde{\mathbf{h}}(\mathrm{n})\|_{\mathrm{G}_{\sigma}}^{2}\right\}+\mu^{2} \sigma_{\mathrm{v}}^{2} \gamma^{\mathrm{T}} \sigma
$$

Equation is stable if the matrix $\mathbf{G}$ is stable [4]. From (61), we know that $\mathbf{G}=\mathrm{I}-\mu \mathbf{M}+\mu^{2} \mathbf{N}$, where $\mathbf{M}=\mathrm{E}\{\mathbf{X}(\mathrm{n}) \mathbf{D}(\mathrm{n})\}$ $\otimes I+I \otimes E\{\mathbf{X}(n) \mathbf{D}(n)\} \quad, \quad$ and $\quad \mathrm{N}=\mathrm{E}\{(\mathbf{X}(\mathrm{n}) \mathbf{D}(\mathrm{n})) \otimes$ $(\mathbf{X}(\mathrm{n}) \mathbf{D}(\mathrm{n}))\}$. The condition on $\mu$ to guarantee the convergence in the mean-square sense of the adaptive algorithms is

$$
0 \leq \mu \leq \min \left\{\frac{1}{\lambda_{\max }\left(\mathbf{M}^{-1} \mathbf{N}\right)}, \frac{1}{\max \left(\lambda(\mathbf{H}) \in \mathbf{R}^{+}\right)}\right\}
$$




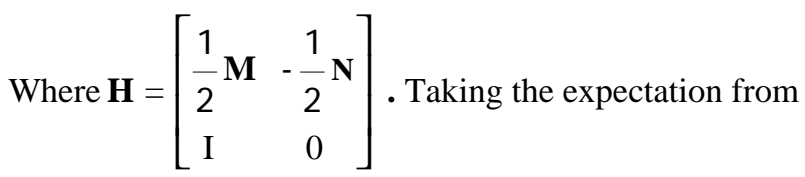
both sides of (50) yields

$$
\mathrm{E}\{\tilde{\mathbf{h}}(\mathrm{n}+1))\}=\left[\mathbf{I}-\mu \mathrm{E}\left\{\mathbf{D}^{\mathrm{T}}(\mathrm{n}) \mathbf{X}^{\mathrm{T}}(\mathrm{n})\right\}\right] \mathrm{E}\{\tilde{\mathbf{h}}(\mathrm{n})\}
$$

From (68), the convergence to the mean of the adaptive algorithm in (46) is guaranteed for any $\mu$ that satisfies

$$
\mu<\frac{2}{\lambda_{\max }\left(\mathrm{E}\left\{\mathbf{D}^{\mathrm{T}}(\mathrm{n}) \mathbf{X}^{\mathrm{T}}(\mathrm{n})\right\}\right)}
$$

\section{APPENDIX C}

\section{GENERIC FILTER UPDATE EQUATION FOR THE FAMILY OF VSS-SPU-APA}

We now proceed by determining the optimum step-size, $\mu^{\mathrm{o}}(\mathrm{n})$, instead of using $\mu$ in the VSS version of (14). This equation can be stated in terms of weight error vector, $\tilde{\mathbf{h}}_{\mathrm{F}}(\mathrm{n})=\mathbf{h}_{\mathrm{t} . \mathrm{F}}-\mathbf{h}_{\mathrm{F}}(\mathrm{n})$, where $\mathbf{h}_{\mathrm{t} . \mathrm{F}}$ is the partial unknown true filter vector, as

$$
\tilde{\mathbf{h}}_{\mathrm{F}}(\mathrm{n}+1)=\tilde{\mathbf{h}}_{\mathrm{F}}(\mathrm{n})-\mu \mathbf{X}_{\mathrm{F}}(\mathrm{n})\left(\mathbf{X}_{\mathrm{F}}^{\mathrm{T}}(\mathrm{n}) \mathbf{X}_{\mathrm{F}}(\mathrm{n})\right)^{-1} \mathbf{e}(\mathrm{n})
$$

Taking the squared Euclidean norm and expectations from both sides of (70),

$$
\begin{aligned}
& \mathrm{E}\left\{\left\|\tilde{\mathbf{h}}_{\mathrm{F}}(\mathrm{n}+1)\right\|^{2}\right\}=\mathrm{E}\left\{\left\|\tilde{\mathbf{h}}_{\mathrm{F}}(\mathrm{n})\right\|^{2}\right\}+ \\
& \mu^{2} \mathrm{E}\left\{\mathbf{e}^{\mathrm{T}}(\mathrm{n})\left(\mathbf{X}_{\mathrm{F}}^{\mathrm{T}}(\mathrm{n}) \mathbf{X}_{\mathrm{F}}(\mathrm{n})\right)^{-1} \mathbf{e}(\mathrm{n})\right\}- \\
& 2 \mu \mathrm{E}\left\{\mathbf{e}^{\mathrm{T}}(\mathrm{n})\left(\mathbf{X}_{\mathrm{F}}^{\mathrm{T}}(\mathrm{n}) \mathbf{X}_{\mathrm{F}}(\mathrm{n})\right)^{-1} \mathbf{X}_{\mathrm{F}}^{\mathrm{T}}(\mathrm{n}) \tilde{\mathbf{h}}_{\mathrm{F}}(\mathrm{n})\right\}
\end{aligned}
$$

Equation (71) can be represented in the form of (72)

$$
\mathrm{E}\left\{\left\|\tilde{\mathbf{h}}_{\mathrm{F}}(\mathrm{n}+1)\right\|^{2}\right\}=\mathrm{E}\left\{\left\|\tilde{\mathbf{h}}_{\mathrm{F}}(\mathrm{n})\right\|^{2}\right\}-\Delta \mu
$$

where $\Delta \mu$ is given by

$$
\begin{aligned}
& \Delta \mu=-\mu^{2} E\left\{\mathbf{e}^{\mathrm{T}}(\mathrm{n})\left(\mathbf{X}_{\mathrm{F}}^{\mathrm{T}}(\mathrm{n}) \mathbf{X}_{\mathrm{F}}(\mathrm{n})\right)^{-1} \mathbf{e}(\mathrm{n})\right\}+ \\
& 2 \mu \mathrm{E}\left\{\mathbf{e}^{\mathrm{T}}(\mathrm{n})\left(\mathbf{X}_{\mathrm{F}}^{\mathrm{T}}(\mathrm{n}) \mathbf{X}_{\mathrm{F}}(\mathrm{n})\right)^{-1} \mathbf{X}_{\mathrm{F}}^{\mathrm{T}}(\mathrm{n}) \tilde{\mathbf{h}}_{\mathrm{F}}(\mathrm{n})\right\}
\end{aligned}
$$

If $\Delta \mu$ is maximized, then mean-square deviation (MSD) will undergo the largest decrease from iteration $\mathrm{n}$ to iteration $n+1$. The optimum step-size will be find with derivation of $\Delta \mu$ with respect to $\mu, \mathrm{d} \mu / \mathrm{d} \mu=0$,

$$
\mu^{\mathrm{o}}(\mathrm{n})=\frac{\mathrm{E}\left\{\mathbf{e}^{\mathrm{T}}(\mathrm{n})\left(\mathbf{X}_{\mathrm{F}}^{\mathrm{T}}(\mathrm{n}) \mathbf{X}_{\mathrm{F}}(\mathrm{n})\right)^{-1} \mathbf{X}_{\mathrm{F}}^{\mathrm{T}}(\mathrm{n}) \tilde{\mathbf{h}}_{\mathrm{F}}(\mathrm{n})\right\}}{\mathrm{E}\left\{\mathbf{e}^{\mathrm{T}}(\mathrm{n})\left(\mathbf{X}_{\mathrm{F}}^{\mathrm{T}}(\mathrm{n}) \mathbf{X}_{\mathrm{F}}(\mathrm{n})\right)^{-1} \mathbf{e}(\mathrm{n})\right\}}
$$

Now by using the following approximation, $\mathbf{X}^{\mathrm{T}}(\mathrm{n}) \tilde{\mathbf{h}}(\mathrm{n}) \approx \mathbf{X}_{\mathrm{F}}^{\mathrm{T}}(\mathrm{n}) \tilde{\mathbf{h} F(n)}$, and neglecting the dependency of $\tilde{\mathbf{h}}_{\mathrm{F}}(\mathrm{n})$ on the past noises, the optimum size in (74) becomes

$$
\mu^{\circ}(\mathrm{n})=\frac{\left.\tilde{\mathrm{E}}^{\mathrm{T}}(\mathrm{h}) \mathbf{X}_{\mathrm{F}}(\mathrm{n})\left(\mathbf{X}_{\mathrm{F}}^{\mathrm{T}}(\mathrm{n}) \mathbf{X}_{\mathrm{F}}(\mathrm{n})\right)^{-1} \mathbf{X}_{\mathrm{F}}^{\mathrm{T}}(\mathrm{n}) \tilde{\mathbf{h}}_{\mathrm{F}}(\mathrm{n})\right\}}{\mathrm{E}\left\{\tilde{\mathbf{h}}_{\mathrm{F}}^{\mathrm{T}}(\mathrm{n}) \mathbf{X}_{\mathrm{F}}(\mathrm{n})\left(\mathbf{X}_{\mathrm{F}}^{\mathrm{T}}(\mathrm{n}) \mathbf{X}_{\mathrm{F}}(\mathrm{n})\right)^{-1} \mathbf{X}_{\mathrm{F}}^{\mathrm{T}}(\mathrm{n}) \tilde{\mathbf{h}}_{\mathrm{F}}(\mathrm{n})\right\}+\sigma_{\mathrm{V}}^{2} \operatorname{Tr}\left(\mathrm{E}\left\{\left(\mathbf{X}_{\mathrm{F}}^{\mathrm{T}}(\mathrm{n}) \mathbf{X}_{\mathrm{F}}(\mathrm{n})\right)^{-1}\right\}\right)}
$$

Substituting the $\mu^{\mathrm{o}}(\mathrm{n})$ of (75) instead of $\mu$ in (14), the family of VSS-SPU-APA is established. Now by defining

$$
\mathbf{q}_{\mathrm{F}}(\mathrm{n})=\mathbf{X}_{\mathrm{F}}(\mathrm{n})\left(\mathbf{X}_{\mathrm{F}}^{\mathrm{T}}(\mathrm{n}) \mathbf{X}_{\mathrm{F}}(\mathrm{n})\right)^{-1} \mathbf{X}_{\mathrm{F}}^{\mathrm{T}}(\mathrm{n}) \tilde{\mathbf{h}}_{\mathrm{F}}(\mathrm{n})
$$

the optimum step-size is given by

$$
\mu^{o}(n)=\frac{E\left\{\left\|\mathbf{q}_{\mathrm{F}}(\mathrm{n})\right\|^{2}\right\}}{\mathrm{E}\left\{\left\|\mathbf{q}_{\mathrm{F}}(\mathrm{n})\right\|^{2}\right\}+\Upsilon}
$$

From the above, the VSS is obtained from (36), where we can estimate $\mathbf{q}_{\mathrm{F}}$ (n) from (37).

\section{REFERENCES}

[1] B. Widrow and S. D. Stearns, Adaptive Signal Processing. Englewood Cliffs, NJ: Prentice-Hall, 1985.

[2] S. Haykin, Adaptive Filter Theory. NJ: Prentice-Hall, 4th edition, 2002.

[3] K. Ozeki and T. Umeda, "An adaptive filtering algorithm using an orthogonal projection to an affine subspace and its properties," in Electron. Commun. Jpn., vol. 67-A, 1984, pp. 19-27.

[4] H.-C. Shin and A. H. Sayed, "Mean-square performance of a family of affine projection algorithms," IEEE Trans. Signal Processing, vol. 52, pp. 90-102, Jan. 2004.

[5] A. H. Sayed, Fundamentals of Adaptive Filtering. Wiley, 2003.

[6] S. Roy and J. J. Shynk, "Analysis of data-reusing LMS algorithm," in Proc. Midwest Symp. Circuits Syst., 1989, pp. 1127-1130.

[7] . Apolinario, M. L. Campos, and P. S. R. Diniz, "Convergence analysis of the binormalized data-reusing LMS algorithm," IEEE Trans. Signal Processing, vol. 48, pp. 3235-3242, Nov. 2000.

[8] H.-C. Shin, W. J. Song, and A. H. Sayed, "Mean-square performance of data-reusing adaptive algorithms," IEEE Signal Processing Letters, vol. 12, pp. 851-854, Dec. 2005.

[9] S. S. Pradhan and V. E. Reddy, "A new approach to subband adaptive filtering,” IEEE Trans. Signal Processing, vol. 47, pp. 655-664, 1999.

[10] M. de Courville and P. Duhamel, "Adaptive filtering in subbands using a weighted criterion," IEEE Trans. Signal Processing, vol. 46, pp. 2359-2371, 1998.

[11] K. A. Lee and W. S. Gan, "Improving convergence of the NLMS algorithm using constrained subband updates," IEEE Signal Processing Letters, vol. 11, pp. 736-739, 2004.

[12] O. W. Kwong and E. D. Johnston, "A variable step size LMS algorithm,” IEEE Trans. Signal Processing, vol. 40, pp. 1633-1642, 1992

[13] J. Mathews and Z. Xie, "Stochastic gradient adaptive filters with gradient adaptive step size," IEEE Trans. Signal Processing, vol. 35, pp. 450-454, 1993.

[14] T. Aboulnasr and K. Mayyas, "A robust variable step-size lms-type algorithm: Analysis and simulations," IEEE Trans. Signal Processing, vol. 45, pp. 631-639, 1997. 
[15] D. I. Pazaitis and A. G. Constantinides, "A novel kurtosis driven variable step-size adaptive algorithm,” IEEE Trans. Signal Processing, vol. 47, pp. 864-872, 1999.

[16] H. C. Shin, A. H. Sayed, and W. J. Song, "Variable step-size NLMS and affine projection algorithms," IEEE Signal Processing Letters, vol. 11, pp. 132-135, Feb. 2004.

[17] S. C. Douglas, "Analysis and implementation of the max-NLMS adaptive filter," in Proc. 29th Asilomar Conf. on Signals, Systems, and Computers, Pacific Grove, CA, Oct. 1995, pp. 659-663.

[18] T. Aboulnasr and K. Mayyas, "Selective coefficient update of gradient-based adaptive algorithms," in Proc. IEEE Int. Conf. on Acoustics, Speech, and Signal Processing, Munich, Germany, Apr. 1997, pp. 1929-1932.

[19] T. Aboulnasr and K. Mayyas, "Complexity reduction of the NLMS algorithm via selective coefficient update," IEEE Trans. Signal Processing, vol. 47, pp. 1421-1424, May 1999.

[20] T. Schertler, "Selective block update NLMS type algorithms," in Proc. IEEE Int. Conf. on Acoustics, Speech, and Signal Processing, Seattle, WA, May 1998, pp. 1717-1720.

[21] K. Do־ganc,ay and O. Tanrikulu, "Adaptive filtering algorithms with selective partial updates," IEEE Trans. Circuits, Syst. II: Analog and Digital Signal Processing, vol. 48, pp. 762-769, Aug. 2001.

[22] S. Werner, M. L. R. de Campos, and P. S. R. Diniz, "Partial-update NLMS algorithms with data-selective updating," IEEE Trans. Signal Processing, vol. 52, no. 4, pp. 938-948, Apr. 2004.

[23] S. L. Gay and J. Benesty, Acoustic Signal Processing for Telecommunication. Boston, MA: Kluwer, 2000.

[24] S. G. Sankaran and A. A. L. Beex, "Normalized LMS algorithm with orthogonal correction factors," in Proc. Asilomar Conf. on Signals, Systems, and Computers, 1997, pp. 1670-1673.

[25] S. G. Kratzer and D. R. Morgan, "The partial-rank algorithm for adaptive beamforming," in Proc. SPIE Int. Soc. Opt. Eng, 1985, pp. 9-14.

[26] D. E. Knuth, Sorting and Searching vol. 3 of The Art of Computer Programming. 2nd ed. Reading, MA: Addison-Wesley, 1973.

[27] S. G. Sankaran and A. A. L. Beex, "Convergence behavior of affine projection algorithms," IEEE Trans. Signal Processing, vol. 48, pp. 1086-1096, 2000.

[28] T. K. Moon and W. C. Sterling, Mathematical Methods and Algorithms for Signal Processing. Upper Saddle River: Prentice Hall,

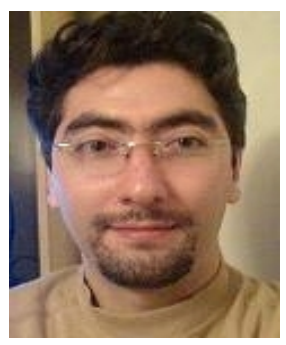

Mohammad Shams Esfand Abadi was born in Tehran, Iran, on September 18, 1978. He received the B.S. degree in Electrical Engineering from Mazandaran University, Mazandaran, Iran and the M.S. degree in Electrical Engineering from Tarbiat Modarres University, Tehran, Iran in 2000 and 2002, respectively, and the Ph.D. degree in Biomedical Engineering from Tarbiat Modarres University, Tehran, Iran in 2007. Since 2004 he has been with the Department of Electrical Engineering, Shahid Rajaee University, Tehran, Iran. During the fall of 2003, spring 2005 , and again in the spring of 2007, he was a visiting scholar with the Signal Processing Group at the University of Stavanger, Norway. His research interests include digital filter theory and adaptive signal processing algorithms

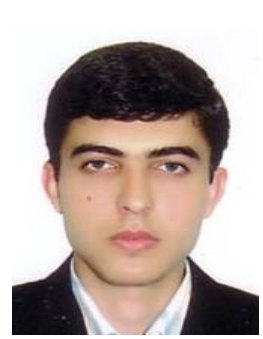

Azizollah gholipour was born in Behshahr, Mazandran, Iran, in 1974. He received the B.Sc. degree in Mohajer institute of technology Isfahan, Iran, in 1999. Since 1999, he has been a Electronic teacher in education. He is the master student in the Shahid Rajaee Teacher Training University, Department of Electrical Engineering Tehran, Iran. His research activities include adaptive signal processing, and adaptive filtering.

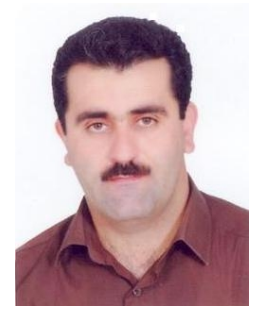

Vahid mehrdad was born in Khoramabad, Iran, in 1985. He received the B.S. degree in electronic engineering from Shahid Rajaee Teacher Training university, Tehran, Iran, in 2007. He is the master student in the Shahid Rajaee Teacher Training University, Department of Electrical Engineering Tehran, Iran. His research activities include adaptive signal processing, and adaptive filtering.

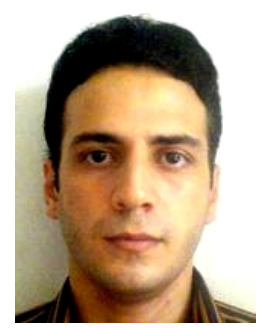

Majid Noroozi was born in Rey, Iran, on February 02, 1988. He is the B.S. student of electronic engineering at Shahid Rajaee Teacher Training University. His research interests include adaptive signal processing. 